\title{
Improving the mean and uncertainty of ultraviolet multi-filter rotating shadowband radiometer in situ calibration factors: utilizing Gaussian process regression with a new method to estimate dynamic input uncertainty
}

\author{
Maosi Chen ${ }^{1}$, Zhibin Sun ${ }^{1}$, John M. Davis ${ }^{1}$, Yan-An Liu ${ }^{2,3,4}$, Chelsea A. Corr ${ }^{1}$, and Wei Gao ${ }^{1,5}$ \\ ${ }^{1}$ United States Department of Agriculture UV-B Monitoring and Research Program, Natural Resource Ecology Laboratory, \\ Colorado State University, Fort Collins, CO 80523, USA \\ ${ }^{2}$ Key Laboratory of Geographic Information Science (Ministry of Education), East China Normal University, \\ Shanghai 200241, China \\ ${ }^{3}$ School of Geographic Sciences, East China Normal University, Shanghai 200241, China \\ ${ }^{4}$ ECNU-CSU Joint Research Institute for New Energy and the Environment, Shanghai 200062, China \\ ${ }^{5}$ Department of Ecosystem Science and Sustainability, Colorado State University, Fort Collins, CO 80523, USA
}

Correspondence: Maosi Chen (maosi.chen@colostate.edu), Zhibin Sun (zhibin.sun@ colostate.edu), and Yan-An Liu (yaliu@geo.ecnu.edu.cn)

Received: 31 August 2018 - Discussion started: 15 November 2018

Revised: 27 January 2019 - Accepted: 28 January 2019 - Published: 12 February 2019

\begin{abstract}
To recover the actual responsivity for the Ultraviolet Multi-Filter Rotating Shadowband Radiometer (UVMFRSR), the complex (e.g., unstable, noisy, and with gaps) time series of its in situ calibration factors $\left(V_{0}\right)$ need to be smoothed. Many smoothing techniques require accurate input uncertainty of the time series. A new method is proposed to estimate the dynamic input uncertainty by examining overall variation and subgroup means within a moving time window. Using this calculated dynamic input uncertainty within Gaussian process (GP) regression provides the mean and uncertainty functions of the time series. This proposed GP solution was first applied to a synthetic signal and showed significantly smaller RMSEs than a Gaussian process regression performed with constant values of input uncertainty and the mean function. GP was then applied to three UV-MFRSR $V_{0}$ time series at three ground sites. The method appropriately accounted for variation in slopes, noises, and gaps at all sites. The validation results at the three test sites (i.e., HI02 at Mauna Loa, Hawaii; IL02 at Bondville, Illinois; and OK02 at Billings, Oklahoma) demonstrated that the agreement among aerosol optical depths (AODs) at the $368 \mathrm{~nm}$ channel calculated using $V_{0}$ determined by the GP mean function and the equivalent AERONET AODs were
\end{abstract}

consistently better than those calculated using $V_{0}$ from standard techniques (e.g., moving average). For example, the average AOD biases of the GP method (0.0036 and 0.0032) are much lower than those of the moving average method (0.0119 and 0.0119) at IL02 and OK02, respectively. The GP method's absolute differences between UV-MFRSR and AERONET AOD values are approximately $4.5 \%, 21.6 \%$, and $16.0 \%$ lower than those of the moving average method at $\mathrm{HIO2,} \mathrm{IL02,} \mathrm{and} \mathrm{OK02,} \mathrm{respectively.} \mathrm{The} \mathrm{improved} \mathrm{accu-}$ racy of in situ UVMRP $V_{0}$ values suggests the GP solution is a robust technique for accurate analysis of complex time series and may be applicable to other fields.

\section{Introduction}

While many instruments generate relatively stable data time series over short time windows, dynamic uncertainty levels, variable sampling densities, and/or different lengths of gaps with missing data can complicate the analysis of long-term datasets. For example, the 5-year time series of a solar variability indicator (Mg II core to wing index) shows consis- 
tency on the order of days but increasing noise level and gaps are observed at the month scale (Cebula et al., 1992). The time series of the geopotential scale factor, a function of the geoidal potential, is also relatively stable on shorter timescales but demonstrates a slowly increasing long-term pattern (Burša et al., 1997). Additionally, the time series of a ratio ( $F$ factor) for calibrating a satellite radiometer suite (i.e., VIIRS) shows band-specific gap distributions and variable trends (Cardema et al., 2012). As a result, these time series may not be described as a simple deterministic function of time due to possible noise and gaps.

Long-term measurements of irradiance by Multi-Filter Rotating Shadowband Radiometers (MFRSRs) are also subject to errors imposed by the factors mentioned above. The MFRSR measures direct normal, diffuse horizontal, and total horizontal irradiances at seven visible channels with a roughly $10 \mathrm{~nm}$ full half maximum width (FHMW) (Harrison and Michalsky, 1994). The Ultraviolet (UV) version of MFRSR measures the same three irradiance components at seven UV channels (i.e., 300, 305, 311, 317, 325, 332, and $368 \mathrm{~nm}$ ) with a $2 \mathrm{~nm}$ FHMW (Gao et al., 2010). Currently, the US Department of Energy (DOE) Atmospheric Radiation Measurement (ARM) Climate Research Facility (Mather and Voyles, 2013), the NOAA Surface Radiation (SURFRAD) (Augustine et al., 2005), and the US Department of Agriculture (USDA) UV-B Monitoring and Research Program (UVMRP) (Gao et al., 2010) maintain their own MFRSR and/or UV-MFRSR at multiple sites across the US. To capture immediate instrument responsivity variation, the UVMRP performs in situ calibrations using the Langley method (Slusser et al., 2000; Harrison and Michalsky, 1994) or derived approaches (e.g., Chen et al., 2013, 2015, 2016) on (UV-)MFRSR direct beam measurements on days with extended clear-sky periods (Gao et al., 2010).

Many factors contribute to the error or uncertainty of the Langley method, including variations in aerosol and/or other atmospheric constituents over the course of the calibration period (Augustine et al., 2003; Chen et al., 2015; Zhang et al., 2016), the presence of thin cirrus (Shaw, 1976), and instrument errors (e.g., instrument tilt and misalignment, incorrect nighttime offset and angular corrections) (Alexandrov et al., 2007). Thus, the sequence of original UVMRP (UV)MFRSR in situ calibration factors exhibits certain levels of noise. Among these uncertainties, variable AOD is considered the major contributor to the variability in the Langley calibration factors obtained in typical atmospheric conditions over the continental United States (Alexandrov et al., 2008), even with careful cloud screening (e.g., Chen et al., 2014; Alexandrov et al., 2004). In addition, extended cloudy periods and low solar zenith angles during winter months further reduce the sequence quality and appear as large time gaps in the datasets. Since the in situ calibration factor represents the instrument's responsivity, which is assumed to be relatively stable, it has been suggested that one applies some smoothing methods (e.g., averaging or fitting a smooth curve) to the daily calibration time series (Alexandrov et al., 2008) to reduce the issue. Currently, UVMRP implements an outlier detection and moving smoothing technique to overcome these issues. However, the process involves manual interaction, performs unreliably during sparse and gapped periods, and lacks the uncertainty estimation.

Analyses of complex long-term time series, such as those of (UV-)MFRSR $V_{0}$ values, must consider (i) the underlying continuous trend (i.e., the mean function) and the corresponding trend uncertainty and (ii) the (dynamic) input uncertainty. For problem (i), there is a variety of available approaches, such as local polynomial regression, smoothing splines, and Gaussian process (GP) regression (Proietti, 2011). Local polynomial regression (LPR) constructs a polynomial within each local time window and fits its coefficients by locally weighted least squares. LPR's computational complexity is low, and it can eliminate some of the randomness in the data (Hyndman, 2011). However, LPR may have difficulty on the cases with varying sampling densities or gaps. In addition, LPR does not allow estimation of the trend near the ends of the time series and cannot be used for forecasting (Hyndman, 2011). A spline is a piecewise polynomial function with continuous derivatives (Proietti, 2011), and smoothing splines estimate the underlying spline by minimizing the distance between the spline and the observations while penalizing the roughness of the spline (Wahba, 2011). For example, a cubic spline fit was used to fill the large gaps in the Mg II index time series (Viereck et al., 2004). Both LPR and smoothing splines are unable to utilize the information about the input uncertainties or to estimate the uncertainty associated with the trend. Unlike the two methods above, GP does not restrict the class of the underlying functions because it is not a parametric model (Rasmussen and Williams, 2006). Instead, it gives a priori probability to every possible function based on the desired function characteristics such as smoothness (Rasmussen and Williams, 2006). GP regression assumes both the observations and the underlying function are from one joint (prior) Gaussian distribution and derives the underlying function distribution by conditioning the joint (prior) distribution on the observations (Rasmussen and Williams, 2006). The method takes the observational error into consideration and naturally gives the uncertainty of the underlying function, making itself an appropriate tool for problem (i). GP regression has been widely used in many fields (e.g., forecasting of mortality rates, Wu and Wang, 2018; prediction of spatial-temporal violent events, Kupilik and Witmer, 2018; and modeling-received signal strength for wireless local area network location fingerprinting, Richter and Toledano-Ayala, 2015).

For problem (ii), the input error statistics (e.g., input uncertainty) is often assumed to be known or roughly estimated in advance. In practice, a typical approach may use some predetermined constant (e.g., the nominal uncertainty of an instrument, or the standard deviation of its observation) to estimate input uncertainty for the entire dataset. However, this kind of 
approach omits the information of the possible time-varying observation error, leading to over- or underestimation of the input uncertainty at a given (temporal) location (Chandorkar et al., 2017). A sophisticated approach may treat the dynamic input uncertainty as additional parameters and solve them together with other model parameters through optimization under the Bayesian framework (Kavetski et al., 2006a, b). However, this method requires the specification of valid error and uncertainty models, which are normally poorly understood in practice (Kavetski et al., 2006a, b).

In this study, we developed and validated a generic solution that combines GP regression with a new dynamic input uncertainty estimation method to determine the underlying continuous trend and the corresponding uncertainty for the given time series. In Sect. 2, we briefly summarize the basics of the GP regression and develop the dynamic input uncertainty estimation method. We also describe a complex (noisy, gapped, etc.) synthetic time series and real UVMFRSR in situ calibration factor time series used in the analysis. In Sect. 3, we present and discuss the performance of the GP method on the test data, in comparison with the UVMRP current operational method and a moving average (MA) technique. Validation of the calibration factors determined with the GP method via the comparison of AODs calculated with these factors and those reported by the AErosol RObotic NETwork (AERONET) (Holben et al., 1998) is also discussed in Sect. 3.

\section{Materials and methods}

\subsection{Gaussian process (GP) regression}

\subsubsection{Main procedure}

A GP is a technique used in the analysis of a finite number of random variables with a joint Gaussian distribution (Rasmussen and Williams, 2006). The following briefly introduces the theory of GP regression. An observed dataset, $\mathcal{D}_{\text {obs }}=(\mathbf{X}, \boldsymbol{y})=\left\{\left(\boldsymbol{x}_{\mathrm{i}}, y_{\mathrm{i}}\right) \mid i=1, \ldots, N\right\}$, has $N$ pairs of inputs $\left(\mathbf{X}=\left\{\boldsymbol{x}_{\mathrm{i}}\right\} \in \mathbf{R}^{N \times D}\right)$ and corresponding observed values $\left(\boldsymbol{y}=\left\{y_{\mathrm{i}}\right\} \in \mathbf{R}^{N}\right.$ ), where $D$ is the length of input vector $\boldsymbol{x}_{\mathrm{i}}$. $\boldsymbol{y}$ is the combination of a function of $\mathbf{X}$ and noises $\boldsymbol{\varepsilon}: \boldsymbol{y}=$ $\mathbf{f}(\mathbf{X})+\boldsymbol{\varepsilon}$, where $\boldsymbol{\varepsilon}$ follows an independent distributed Gaussian distribution $\varepsilon \sim \mathcal{N}\left(\mathbf{0}, \operatorname{diag}\left(\boldsymbol{\sigma}_{\mathbf{y}}^{2}\right)\right)$ and $\boldsymbol{\sigma}_{\mathbf{y}} \in \mathbf{R}^{N}$ is the given or estimated uncertainty (standard deviation) on the $N$ observations. In practice, $\sigma_{\mathbf{y}}$ is not always known in advance. Section 2.1.2 provides an empirical approach to estimating $\sigma_{\mathbf{y}}$. It is assumed that the test dataset $\mathcal{D}_{*}=\left(\mathbf{X}_{*}, \boldsymbol{f}_{*}\right)=$ $\left\{\left(\boldsymbol{x}_{* i}, f_{* i}\right) \mid i=1, \ldots, N_{*}\right\}$ and the observed dataset $\left(\mathcal{D}_{\mathrm{obs}}\right)$ have the joint Gaussian distribution but the test function values $\left(f_{*}\right)$ are unknown:

$\left[\begin{array}{c}\boldsymbol{y} \\ \boldsymbol{f}_{*}\end{array}\right] \sim \mathcal{N}\left(\mathbf{0},\left[\begin{array}{ll}\mathbf{K}_{\mathbf{X X}}+\boldsymbol{\sigma}_{\mathbf{y}}^{2} \mathbf{I} & \mathbf{K}_{\mathbf{X X}} \\ \mathbf{K}_{\mathbf{X X}} & \mathbf{K}_{\mathbf{X}_{*}} \mathbf{X}_{*}\end{array}\right]\right)$,

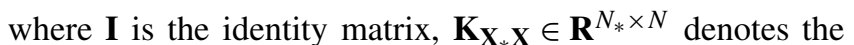
covariance matrix between observed $\left(\mathbf{X}_{*}\right)$ and test inputs $(\mathbf{X})$, and similarly for the other three terms $\mathbf{K}_{\mathbf{X X}} \in \mathbf{R}^{N \times N}$, $\mathbf{K}_{\mathbf{X} \mathbf{X}_{*}} \in \mathbf{R}^{N \times N_{*}}$, and $\mathbf{K}_{\mathbf{X}_{*} \mathbf{X}} \in \mathbf{R}^{N_{*} \times N}$. Each element of these covariance matrices is determined by a kernel function $K\left(z_{1}, z_{2}\right)$, which maps any pair of inputs $\left(z_{1}, z_{2} \in \mathbf{R}^{D}\right)$ into $\mathbf{R}$. There is a wide variety of kernel functions such as the radial basis function (RBF) and the rational quadratic (RQ) kernel (Rasmussen and Williams, 2006). For example, The RQ kernel is defined by the following equation with length scale $(l)$ and alpha $(\alpha)$ as its two parameters (Rasmussen and Williams, 2006):

$K_{\mathrm{RQ}}(r)=\left(1+\frac{r^{2}}{2 \alpha l^{2}}\right)^{-\alpha}, r=\left\|z_{1}-z_{2}\right\|$.

In practice, users need to use prior knowledge or techniques such as autocorrelation to choose the best kernel function to represent the correlation among input data. The hyperparameters $(\boldsymbol{\theta})$ of the chosen kernel function are then optimized by maximizing the log-transformed marginal likelihood (Rasmussen and Williams, 2006):

$$
\begin{gathered}
\log p(\boldsymbol{y} \mid \mathbf{X}, \boldsymbol{\theta})=-\frac{1}{2} \boldsymbol{y}^{T}\left[\mathbf{K}_{\mathbf{X X}}(\boldsymbol{\theta})+\boldsymbol{\sigma}_{\boldsymbol{y}}^{2} \mathbf{I}\right]^{-1} \\
\boldsymbol{y}-\frac{1}{2} \log \left|\mathbf{K}_{\mathbf{X X}}(\boldsymbol{\theta})+\boldsymbol{\sigma}_{\boldsymbol{y}}^{2} \mathbf{I}\right|-\frac{N}{2} \log 2 \pi .
\end{gathered}
$$

To simplify the calculation, the mean of $\boldsymbol{y}$ has been subtracted from both the actual observed values and the test function values. Therefore, the joint distribution has a mean equal to zero.

Based on the (optimized) joint distribution Eq. (1), the theorem that derives the conditional distribution from the joint Gaussian distribution (Eaton, 1983), and the inversion equations of a partitioned matrix (Press, 1992), the GP regression predicts $\boldsymbol{f}_{*}$ from given $\mathbf{X}, \boldsymbol{y}$, and $\mathbf{X}_{*}$ (Rasmussen and Williams, 2006):

$\left\{\boldsymbol{f}_{*} \mid \mathbf{X}, \boldsymbol{y}, \mathbf{X}_{*}\right\} \sim \mathcal{N}\left(\overline{\boldsymbol{f}}_{*}, \operatorname{cov}\left(\boldsymbol{f}_{*}\right)\right)$,

where

$\bar{f}_{*}=\mathbf{K}_{\mathbf{X}_{*} \mathbf{X}}\left[\mathbf{K}_{\mathbf{X X}}+\sigma_{\boldsymbol{y}}^{2} \mathbf{I}\right]^{-1} \boldsymbol{y}$,

$\operatorname{cov}\left(\boldsymbol{f}_{*}\right)=\mathbf{K}_{\mathbf{X}_{*} \mathbf{X}_{*}}-\mathbf{K}_{\mathbf{X}_{*} \mathbf{X}}\left[\mathbf{K}_{\mathbf{X X}}+\boldsymbol{\sigma}_{\mathbf{y}}^{2} \mathbf{I}\right]^{-1} \mathbf{K}_{\mathbf{X X}}$.

The GP-predicted sample standard deviations (i.e., the square root of the diagonal elements in $\left.\operatorname{cov}\left(\boldsymbol{f}_{*}\right)\right)$ can be converted to the predicted confidence intervals. For example, the predicted 0.99999 confidence intervals used in this study are obtained by multiplying a constant (i.e., 4.42) with predicted sample standard deviation. Points outside the predicted confidence intervals may be considered outliers and can be excluded iteratively until all points are within the confidence intervals or the average ratio between GP predicted means and standard deviations is less than a threshold (e.g., the threshold is 0.01 in this study). 


\subsubsection{Proposed dynamic input uncertainty estimation}

As mentioned before, the statistical properties of the noise $\boldsymbol{\varepsilon}$ of the observed time series $\boldsymbol{y}$ might be unknown. Even if assuming $\boldsymbol{\varepsilon} \sim \mathcal{N}\left(\mathbf{0}, \operatorname{diag}\left(\boldsymbol{\sigma}_{\boldsymbol{y}}^{2}\right)\right)$ in practice, $\boldsymbol{\sigma}_{\boldsymbol{y}}$ is not always a constant and could vary in time. Therefore, we propose to estimate $\sigma_{y}$ with a moving window approach. Within each moving window $(\mathrm{W})$, the input uncertainty (denoted as $s_{\mathrm{i}}$ ) is assumed to be relatively stable and can be estimated using all points in the window (W). Note that $s_{\mathrm{i}}$ is not equivalent to the standard deviation of all points within the period $\left(s_{\mathrm{W}}\right)$, unless the mean function of the time series is invariant. We derive the relationship between $s_{\mathrm{i}}$ and $s_{\mathrm{W}}$ (see Appendix A for the detailed derivation) to estimate $s_{\mathrm{i}}$ :

$s_{\mathrm{W}}^{2}=\frac{N-J}{N-1} s_{\mathrm{i}}^{2}+\frac{1}{N-1} \sum_{j=1}^{J} N_{j}\left(\mu_{j}-\mu_{\mathrm{W}}\right)^{2}$,

where all points within $\mathrm{W}$ are clustered into $J$ subgroups based on their similarity in both time and value; $N_{j}$ is the number of points in each subgroup $j ; N=\sum_{j=1}^{J} N_{j}$ is the number of all points within $\mathrm{W} ; \mu_{j}$ is the mean of subgroup $j$, which can vary among subgroups; $s_{\mathrm{i}}$ is the estimated uncertainty of each point within $\mathrm{W}$, acting as the sample standard deviation across all subgroups; and $\mu_{\mathrm{W}}$ and $s_{\mathrm{W}}$ are the mean and sample standard deviation of all points within W. The classic $K$-means algorithm was used for the clustering process. To increase the reliability of estimating statistics (mean or sample standard deviation), small subgroups are merged with adjacent ones to ensure each subgroup has more than the required minimum points. The numbers of initial subgroups and the required minimum points depend on the prior knowledge of the variability and availability of the data. Sensitivity studies (not shown) indicate that five initial subgroups per moving window and three required minimum points per subgroup worked well for our applications. The dynamic input uncertainty estimation process is applied to every data point in a sequence. The squares of the estimated input standard deviations (i.e., $s_{\mathrm{i}}^{2}$ in Eq. 7) are stored on the respective diagnostic positions in $\sigma_{y}$.

The flowchart of the proposed dynamic input uncertainty estimation method and the complete GP procedure of estimating the mean and confidence interval functions of a given time series is presented in Fig. 1.

\subsection{Moving average (MA)}

MA is a simple smoothing technique. To assess the performance of the GP regression with other methods, this study implements MA for a one-dimensional case as follows. For a given $x_{* i}$, we first choose its nearby observations $\left\{(x, y)|| x-x_{* i} \mid \leq\right.$ win_size, $\left.(x, y) \in \mathcal{D}_{\text {obs }}\right\}$ within the given window win_size and then calculate the mean $y$ value of the subset as the smoothed observation at $x_{* i}$. The process is repeated for all possible $x$ values in $\mathcal{D}_{*}$. The parameter win_size of MA is set at 20 for all applicable cases in this study.

\subsection{UVMRP operational algorithm (OPER)}

UVMRP operational algorithm (OPER) was specially designed for smoothing its in situ calibration factor sequences (http://uvb.nrel.colostate.edu/UVB/dataProcessingInfo/ VnaughtsDataProcessing.jsf, last access: 8 August 2018). OPER is included as an additional source for method comparison. The algorithm has three steps. In the first step, a 12-count running mean and the corresponding standard deviation are maintained to detect outliers (i.e., points outside half of the running mean or 2 standard deviations). During the process, if three consecutive points are determined to be outliers, visual examination is performed to determine if a permanent change in the instrument responsivity has occurred. If such a change is confirmed, calculation of a new running mean begins on the three points. In the second step, a moving linear regression (LR) is used to smooth the values at the center of each moving window. The moving window size is \pm 3 months. If visual examination finds significant value changes on a date of interest (the center of a moving window), the regression is not performed on that date. In the final step, the regression results from step two are used as input into a weighted means algorithm to generate continuous and smooth in situ calibration factors. The inverse of year fraction between the current date of interest and the date of each participating point is used to calculate the weights. The weighting window is also \pm 3 months from the date of interest.

\subsection{Validation method for $368 \mathrm{~nm}$ in situ calibration factors}

Ideally, to avoid additional uncertainties caused by the interpolation among wavelengths, the calibration factors should be validated via a direct comparison of direct sun signals from the to-be-calibrated UV-MFRSR and a reference instrument measuring at the $368 \mathrm{~nm}$ channel (e.g., the standard precision filter radiometer (PFR) operated by the Physikalisches-Meteorologisches Observatorium Davos, World Optical Depth Research Calibration Center (WORCC)). However, such reference measurements are not available at most UVMRP stations. Therefore, the estimated mean normalized $V_{0}\left(V_{0, \text { norm }}\right)$ values from the GP regression and the other two comparison methods (i.e., MA and OPER) are validated indirectly in terms of aerosol optical depth (AOD) against those obtained at the collocated AERONET sites. As shown in Appendix C, the uncertainty of UV-MFRSR AODs exceeds the World Meteorological Organization (WMO) U95 criterion (e.g., $95 \%$ of the measured data have uncertainty in the range of $0.005 \pm 0.01$ per air mass; Kazadzis et al., 2018) at the UVMRP sites investigated here because the stability assumption of the Langley method 

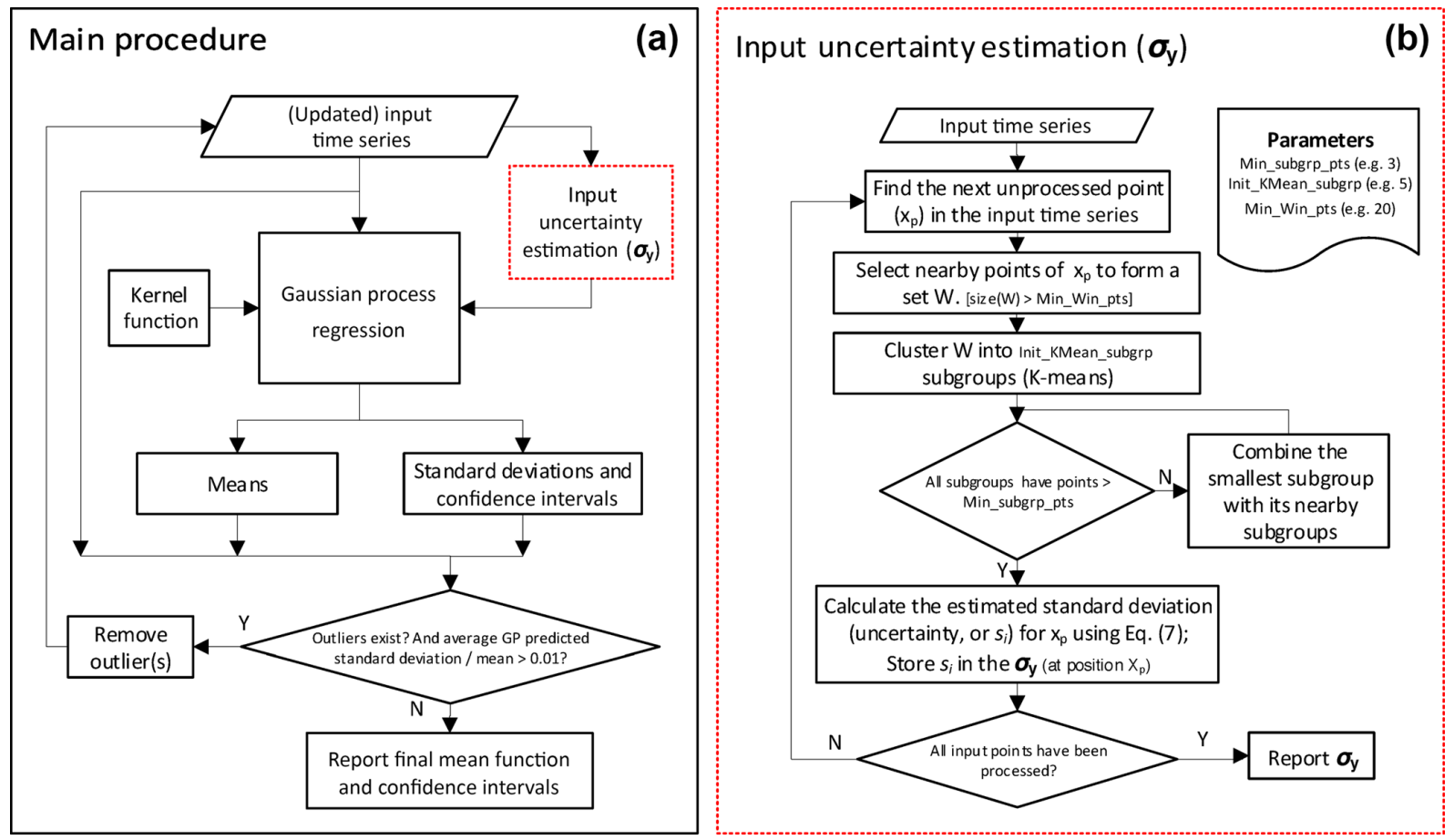

Figure 1. Main procedure for deriving the mean and confidence interval functions using Gaussian process regression (a) and detailed procedure of the proposed input uncertainty estimation method (b).

may not be strictly fulfilled. Therefore, the AOD comparison in this study can only serve as indirect evidence to verify whether the calibration of UV-MFRSR is reasonably accurate. AERONET sun photometers are routinely calibrated with the uncertainty of AOD around 0.002 to 0.005 in the visible range and up to 0.01 in the UV region (Eck et al., 1999; Holben et al., 2001) and are therefore considered a reliable source for AOD intercomparison and radiometer validation (e.g., Alexandrov et al., 2002, 2008; Augustine et al., 2003; Krotkov et al., 2005a, b; Kassianov et al., 2007; Tang et al., 2013; Yin et al., 2015; Zhang et al., 2016). During the recent Fourth WMO Filter Radiometer Comparison held in Davos, Switzerland (between 28 September and 16 October 2015), most AOD values derived from the three AERONET CIMEL sun photometers are within the \pm 0.01 range compared with the PFR triad standard (Kazadzis et al., 2018). This includes those determined at $368 \mathrm{~nm}$ from the extrapolation of AERONET AODs at 340 and $380 \mathrm{~nm}$. The 2015 Davos campaign also included four MFRSR instruments. Overall, the results showed good agreement among the four MFRSRs and the PFR triad standard, though one instrument exhibited a positive bias and low precision compared to the sun-pointing instruments (Kazadzis et al., 2018). However, such errors were likely explained by instrument-specific uncertainties (e.g., angular response correction, responsivity calibration, and shadowband position issues) and do not suggest inherent error in MFRSR AODs (Kazadzis et al., 2018). Augustine et al. (2003) compared SURFRAD MFRSR AODs at the Table
Mountain station in Colorado with UVMRP MFRSR AODs at the Pawnee station ( $85 \mathrm{~km}$ northeast of Table Mountain) and with National Renewable Energy Laboratory (NREL) sun-photometer-derived AODs at Golden station $(50 \mathrm{~km}$ to the south). The AOD difference in the test cases showed a magnitude of 0.1 to 0.2 and was variable over time even for the same comparison site. Krotkov et al. (2005a, b) validated the UVMRP UV-MFRSR AODs with the interpolated AERONET AODs at the $368 \mathrm{~nm}$ at the National Aeronautics and Space Administration Goddard Space Flight Center (NASA/GSFC) site in Greenbelt, Maryland. They found that the UV-MFRSR AODs at $368 \mathrm{~nm}$ channel on cloud-free days had a daily RMSE of less than 0.01 when calibrated using AERONET measurements and increased to approximately 0.02-0.05 (depending on the season) when calibrated using the standard Langley method (Harrison and Michalsky, 1994; Slusser et al., 2000). Alexandrov et al. (2002) developed a comprehensive calibration method for the VIS-MFRSR and validated the calibration at the four channels (i.e., 440, 500,670 , and $870 \mathrm{~nm}$ ) by comparing the derived AOD values with interpolated AERONET values at the ARM Cloud and Radiation Testbed (CART) site. The results showed a small AOD difference (i.e., <0.005) at the 440, 500, and $870 \mathrm{~nm}$ channels for a variety of atmospheric conditions with AODs ranging from 0.03 to 0.4 (at $500 \mathrm{~nm}$ ). Alexandrov et al. (2008) considered optical depth of $\mathrm{NO}_{2}$ and ozone during the MFRSR AOD calculation, although they were small enough to be ignored (i.e., $0.008 \mathrm{NO}_{2}$ optical depth at $415 \mathrm{~nm}$ 
and 0.005 ozone optical depth at $615 \mathrm{~nm}$ ) at their test location at the ARM Southern Great Plains (SGP) site. The long-term intercomparison showed a good agreement (i.e., difference between them $<0.01$ ) between the MFRSR and AERONET AODs at the 440,675, and $870 \mathrm{~nm}$ channels. Kassianov et al. (2007) validated the MFRSR-retrieved optical properties and reported small RMSE values (i.e., 0.00430.0075) among MFRSR, AERONET, and normal incidence multifilter radiometer (NIMFR) AODs at the 500 and $870 \mathrm{~nm}$ channels during the ARM program's Aerosol Intensive Operational Period (IOP) in 2003.

In this study, for the UV-MFRSR at the $368 \mathrm{~nm}$ channel, AOD (AOD $368 \mathrm{~nm}, \mathrm{UVMRP}$ ) is calculated by subtracting Rayleigh optical depth (RLOD $368 \mathrm{~nm}$,UVMRP) from total optical depth (TOD $368 \mathrm{~nm}$, UVMRP) under cloud-free conditions. The absorption of $\mathrm{O}_{3}, \mathrm{NO}_{2}$, and other trace gases is very small at the $368 \mathrm{~nm}$ channel (e.g., $\mathrm{NO}_{2}$ optical depth is around 0.002 to 0.003 at AERONET Cart_Site), so they are ignored during the calculation of $\mathrm{AOD}_{368} \mathrm{~nm}$,UVMRP:

$$
\begin{aligned}
& \mathrm{AOD}_{368 \mathrm{~nm}, \mathrm{UVMRP}} \approx \mathrm{TOD}_{368 \mathrm{~nm}, \mathrm{UVMRP}} \\
& \quad-\mathrm{RLOD}_{368} \mathrm{~nm}, \mathrm{UVMRP} .
\end{aligned}
$$

TOD is calculated using Beer's law (e.g., Slusser et al., 2000), for which the actual calibration factor at the top of the atmosphere $\left(V_{0, \text { raw }}\right)$ is restored from GP-estimated mean $V_{0, \text { norm. }}$. The cosine-corrected voltage and air mass are obtained from the UVMRP web page (https://uvb. nrel.colostate.edu/UVB/da_queryCosCorrected.jsf, last access: 8 August 2018). RLOD is calculated by following the equations in Bodhaine et al. (1999). The site latitude and height for RLOD calculation are from the UVMRP web page (https://uvb.nrel.colostate.edu/UVB/uvb-siteinfo.jsf, last access: 8 August 2018), and the instantaneous site-level surface pressure for RLOD calculation is obtained from the collocated AERONET sites (https://aeronet.gsfc.nasa.gov/ cgi-bin/webtool_opera_v2_new, last access: 31 July 2018).

To obtain reliable AOD values, UV-MFRSR measurements with quality concerns or cloud contamination are excluded in the following comparison. More specifically, (1) any measurements with UVMRP-provided quality control flag(s) relevant to the data quality of the direct beam at the $368 \mathrm{~nm}$ channel are excluded; (2) data with small (direct beam) measurements at $368 \mathrm{~nm}$ are also excluded because they are more sensitive to noise or errors introduced during various calibration steps; and (3) a simple variation check is performed to reduce the potential of mixing cloud and AOD. If the ratio between the standard deviation of TODs and the mean TOD value in the 15 min time window exceeds 0.05 , they are excluded from further analyses.

AERONET (v2.0) provides AOD at the 340 and $380 \mathrm{~nm}$ channels. These values are interpolated to the effective wavelength of the UV-MFRSR $368 \mathrm{~nm}$ channel for comparison using the Ångström exponent as follows. Note that in the log-transformed coordinate system (i.e., $\log (\mathrm{AOD})$ vs. $\log ($ wavelength $)), \log (\mathrm{AOD})$ is generally linear between 340 and $380 \mathrm{~nm}$ (Krotkov et al., 2005a). First, the AERONET AOD spectrum between the two wavelengths is derived by linear interpolation of AERONET AODs at 340 and $380 \mathrm{~nm}$ in the log-transformed coordinate system. Next, since the UV-MFRSR AOD at $368 \mathrm{~nm}$ is a band-pass value over a narrow band (i.e $2 \mathrm{~nm}$ FHMW), the equivalent AERONET AOD at that channel is derived by

$\mathrm{AOD}_{368 \mathrm{~nm}, \mathrm{AERONET}}=\frac{\int_{340 \mathrm{~nm}}^{380 \mathrm{~nm}} \mathrm{AOD}_{\lambda} F_{\lambda} \mathrm{d} \lambda}{\int_{340 \mathrm{~nm}}^{380 \mathrm{~nm}} F_{\lambda} \mathrm{d} \lambda}$,

where $\mathrm{AOD}_{\lambda}$ is the interpolated AERONET AOD spectrum, $F_{\lambda}$ is the spectral response function of the UV-MFRSR at the $368 \mathrm{~nm}$ channel (http://uvb.nrel.colostate.edu/UVB/da queryFilterFunctions.jsf, last access: 8 August 2018), and the wavelength interval for the integral is $0.05 \mathrm{~nm}$. Note that negative AERONET AOD measurements are excluded from the validation because of using log transformation.

Since AERONET and UV-MFRSR AOD values at $368 \mathrm{~nm}$ are derived from measurements involving different instruments and wavelengths, the uncertainties when comparing these AOD values should be noted. Some important sources of uncertainties include the following.

1. AERONET calibration error. At the time of calibration at Mauna Loa Observatory, AERONET reference instruments have an uncertainty of $\sim 0.2 \%$ to $0.5 \%$, which is equivalent to a 0.002 to 0.005 uncertainty in AERONET AOD (Holben et al., 2001). These calibration factors are likely to shift within the year following calibration, which may result in a total AOD uncertainty of $\sim 0.01$ to 0.02 (wavelength dependent, higher in the UV) (Holben et al., 2001).

2. Instrument field of view (FOV). AERONET CIMELs have a FOV of $1.2^{\circ}$ while the UV-MFRSR has a larger FOV (e.g., $\sim 6.5^{\circ}$; reported by Kazadzis et al., 2018). AODs obtained from instruments with larger FOVs are associated with greater AOD uncertainty due to larger contributions of scattered light to the direct irradiance measurement (Kim et al., 2005).

3. Instrument maintenance. Periodic soiling and cleaning of the UV-MFRSR diffuser can result in spurious increases and decreases in AOD, respectively. The frequency of on-site maintenance (e.g., cleaning of the UVMFRSR dome) as well as rainfall events may therefore account for some of the AOD difference (Kim et al., 2005, 2008).

4. Trace gases. As mentioned above, AERONET AOD accounts for $\mathrm{NO}_{2}$ optical depth (e.g., $\sim 0.002-0.003$ at OK02) while UV-MFRSR AOD does not. 


\subsection{Datasets}

\subsubsection{Synthetic case}

We generate a synthetic time series that is composed of six segments with a varying base function and noise levels (Fig. 2a). The base function (Eq. 10), including linear, quadratic, and cubic functions, simulates a wide variety of functions for which the proposed technique is applicable. The noise levels are the same within each segment but different across segments. The noise at segment $i$ is sampled from a fixed normal distribution $\mathcal{N}\left(0, \sigma_{i}^{2}\right)$, where $\sigma_{i}$ is equal to 4 , $8,6,15,7$, and 3 from left to right segments. Each segment originally contains 200 points. Their $x$ coordinates are sampled randomly from six uniform distributions within their domains. Points with $x$ coordinates in the three designated windows (i.e., [64.2, 69.2], [80.8, 85.8], and [122.5, 127.5]) are removed to simulate data gaps in reality.

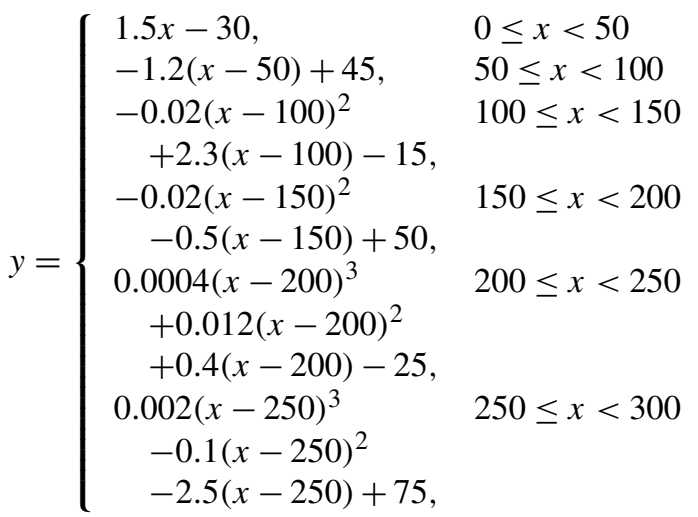

\subsubsection{Application cases: in situ calibration factors}

In this study, the in situ calibration factors of UVMRP UVMFRSRs are used as application cases to test the performance of the three smoothing methods (i.e., GP, MA, and OPER). These UV-MFRSR in situ calibration factors over several months or years are obtained through the Langley method on clear days. Their varying uncertainties are mainly attributed to two aspects. One is the optical stability of atmospheric constituents (e.g., the aerosol, ozone, and thin clouds) when the in situ calibration factor is derived (Chen et al., 2015), and the other is the aging status of the radiometer. UVMRP publish its in situ calibration factors on their website (http://uvb.nrel.colostate.edu/UVB/da_ queryVoIntercepts.jsf, last access: 8 August 2018). To reduce the chances of abrupt changes in the sequences, the data associated with the same instrument (i.e., UV-MFRSR) at the same UVMRP site (denoted as a deployment period) are processed together. Three UVMRP sites with collocated AERONET sites (for validation) were selected (Table 1). The in situ calibration factors at these UVMRP sites represent time series with contrasting densities, noisiness, and slopes (Table 1). Appendix B uses the Oklahoma site (OK02) to
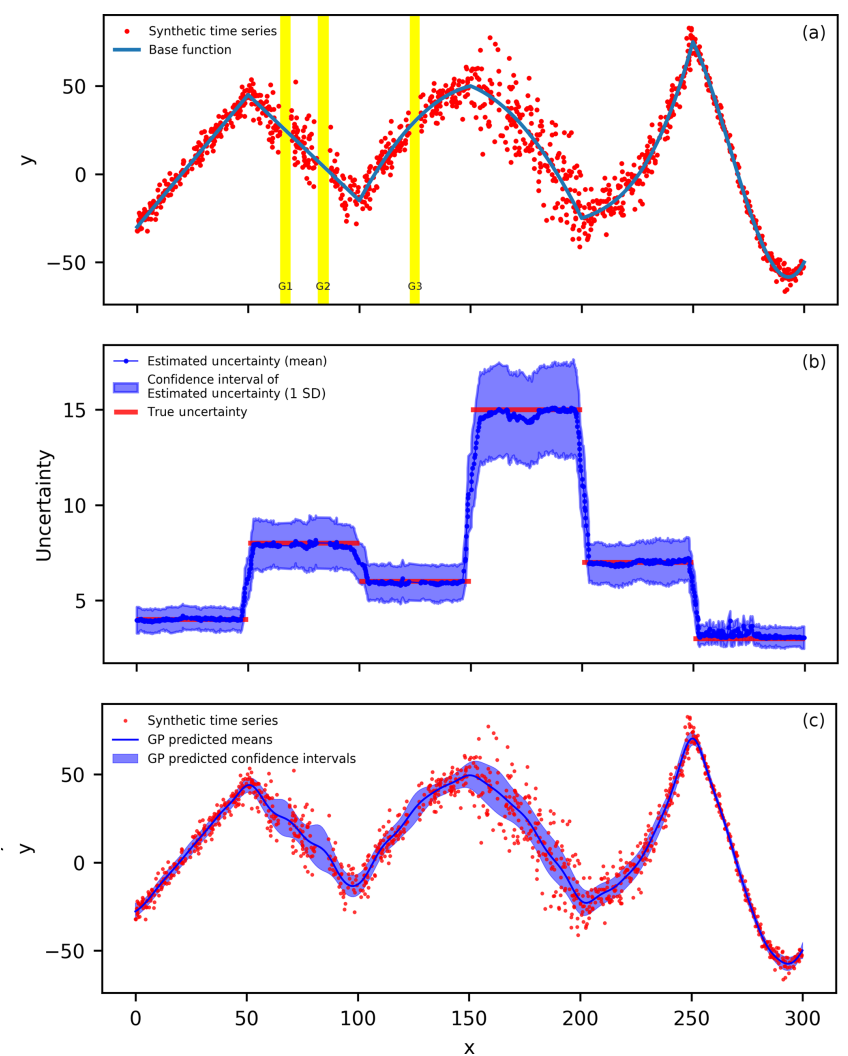

Figure 2. (a) The synthetic time series based on Eq. (10) (the blue line) with varying noise levels. There are originally 200 samples within every 50-wide interval (or segment) in the $x$ coordinate, but points between [64.2, 69.2] (highlighted in yellow, G1), [80.8, 85.8] (highlighted in yellow, G2), and [122.5, 127.5] (highlighted in yellow, G3) are removed to simulate data gaps in practice. The final number of points in the sequence is 1140 . (b) The means (dark blue circles) and confidence intervals (light blue area) of the estimated uncertainty for the 200 synthetic sequences (all sampled from the distribution of (a) but with different random noise). The true uncertainty (red line segments) is also displayed. (c) The Gaussian process regression results for the synthetic time series from (a). The dark blue line is the predicted mean function and the light blue area is the corresponding confidence intervals.

show that the UV-MFRSR $368 \mathrm{~nm}$ in situ calibration factors obey normal distribution.

\section{Results and discussion}

\subsection{Synthetic case}

\subsubsection{Estimation of input uncertainty for Gaussian process}

The proposed dynamic input uncertainty estimation method is first applied to the synthetic case. To observe the statistical properties and characteristics of the estimated input uncertainty, this procedure was applied to 200 synthetic time 
Table 1. The three UVMRP $368 \mathrm{~nm}$ UV-MFRSR in situ calibration factor time series for test.

\begin{tabular}{|c|c|c|c|c|c|}
\hline $\begin{array}{l}\text { UVMRP site } \\
\text { name }\end{array}$ & UVMRP site location & $\begin{array}{l}\text { Collocated AERONET } \\
\text { site }\end{array}$ & Deployment start and end dates & $\begin{array}{l}\text { Figure (original } \\
\text { time series) }\end{array}$ & Time series characteristics \\
\hline HI02 & $19.54^{\circ} \mathrm{N}, 155.58^{\circ} \mathrm{W}, 3409 \mathrm{~m}$ & Mauna_Loa & 17 September 2015 to 1 July 2018 & Fig. 3a1 & dense, low noise, variable slope \\
\hline ILO2 & $40.05^{\circ} \mathrm{N}, 88.37^{\circ} \mathrm{W}, 213 \mathrm{~m}$ & BONDVILLE & 21 March 2017 to 29 May 2018 & Fig. 3b1 & sparse, high noise, sharper slope \\
\hline OK02 & $36.60^{\circ} \mathrm{N}, 97.49^{\circ} \mathrm{W}, 317 \mathrm{~m}$ & Cart_Site & 17 January 2007 to 11 June 2011 & Fig. $3 \mathrm{c} 1$ & $\begin{array}{l}\text { medium density, medium noise, } \\
\text { variable slope }\end{array}$ \\
\hline
\end{tabular}

series, each of which is generated by adding random noise into the base function (Eq. 10) following the procedures discussed in Sect. 2.5.1.

Figure $2 \mathrm{~b}$ shows the means (dark blue circles) and confidence intervals (light blue area) of estimated uncertainty of the 200 estimated input uncertainty sequences. The mean of the estimated uncertainty is close to the true uncertainty $(\mathrm{RMSE}=0.6321)$ for the entire synthetic case as demonstrated by a LR between estimated and true uncertainty with a slope close to 1 (i.e., 1.0332) and a high $R^{2}$ of 0.9759 (Table 2). Most true uncertainty (red line segments) is covered by the confidence intervals except for the areas near the ends of the six segments. In these areas, the method averaged the uncertainty from the adjacent segments and presented a smooth transition between segments. This small RMSE value suggests that using smaller subgroup size (e.g., three to six points) does not significantly influence the estimation of uncertainty (Fig. 2a). Therefore, smaller subgroups are preferred over larger ones as larger subgroups are more likely to have gap(s) with large variation, which tends to increase its estimated standard deviation (Eq. 7).

To demonstrate the improvements in the GP resulting from the dynamic input uncertainty estimation, the GP is also run with three typical constant input uncertainties: overall standard deviation of the synthetic time series (30.95), minimum true uncertainty of the synthetic time series (2.00), and maximum true uncertainty of the synthetic time series (15.00). The results from all three constant input uncertainties are less accurate than the estimated input uncertainty generated by the proposed method (Table 2). The proposed method has a significantly smaller RMSE (i.e., 0.6321) compared with the three constant input uncertainties (i.e., 24.1152, 6.5226, and 8.7921, respectively). Similarly, the LR between the estimated and true uncertainties shows that the proposed method has slope and $R^{2}$ values both close to 1 (i.e., 1.0332 and 0.9759) while the three constant uncertainties show no (linear) correlation with true uncertainties (i.e., the slope and $R^{2}$ values close to zero).

\subsubsection{Estimation of means and confidence interval and its validation}

The kernel function in the GP regression used in this study is the RQ kernel, with two parameters: length scale and alpha (Eq. 2). To use RQ with GP regression, we need to provide the initial (estimated) values for these two parameters. First, we round the original data points (red points in Fig. 2a) to the nearest 0.25 interval grids. Then, we calculate the autocorrelation on these rounded data points from lags of 0.25 to 22.25 (approximately equivalent to lags of 1 to 90 points). Next, we perform curve fitting on autocorrelation results and obtain 9.80 and 1.05 as initial length scale and alpha estimates, respectively. With these initial RQ parameters and the estimated input uncertainty (from the proposed method or using three representative constant input uncertainties), GP regression predicts the mean and uncertainty functions. Figure $2 \mathrm{c}$ shows the GP results for the proposed method: dark blue line for the mean function and the light blue area for the confidence intervals (4.42 times of the GP-predicted uncertainty function).

In terms of the GP-predicted mean function vs. the base function (Eq. 10), the proposed input uncertainty estimation method shows a $12.0 \%$ to $15.7 \%$ improvement on RMSE over the three constant input uncertainties (i.e., 1.1785 vs. 1.3146, 1.3976, and 1.3146) (Table 2). Similarly, the slope of the LR between the two functions is closer to 1 for the proposed uncertainty estimation method (i.e., 1.0082) than the three constant uncertainties (i.e., 1.0228). In addition, the predicted mean function from the proposed method is close to the base function even near the gaps (G1, G2, and G3 in Fig. 2a, c). Additionally, the proposed method's predicted uncertainty function (or confidence intervals) shows better agreement with the true uncertainty of the synthetic time series (Fig. 2c) while the three constant input uncertainties' results show a consistent over- or underestimated pattern over the entire time series (figures not shown). It is noted that the predicted confidence intervals from the proposed method are wider near the three gaps (G1, G2, and G3 in Fig. 2a) than nearby locations with similar uncertainty. This is anticipated because the constraint in the gaps are from distant points at which the RQ kernel gives low correlation.

\subsection{In situ calibration factors cases}

\subsubsection{Applications}

The same GP procedure is applied to three in situ calibration factor $\left(V_{0, \text { norm }}\right.$, sun-earth distance normalized) sequences from three UVMRP deployment periods (Fig. 3) at three different UVMRP locations previously described in Table 1.The Hawaii site (HI02) sits at a clean, high-altitude location, which means its atmospheric condition is more stable 
(a)

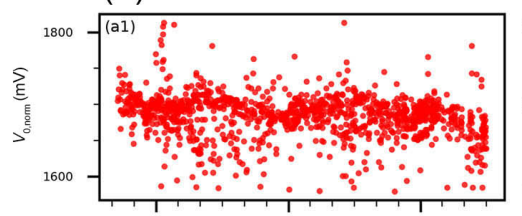

Original in situ calibration factor sequence

(b) - In situ calibration factor

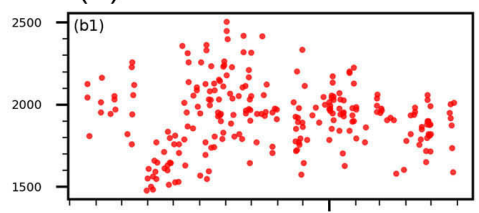

(c)

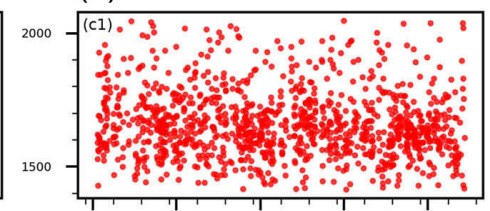

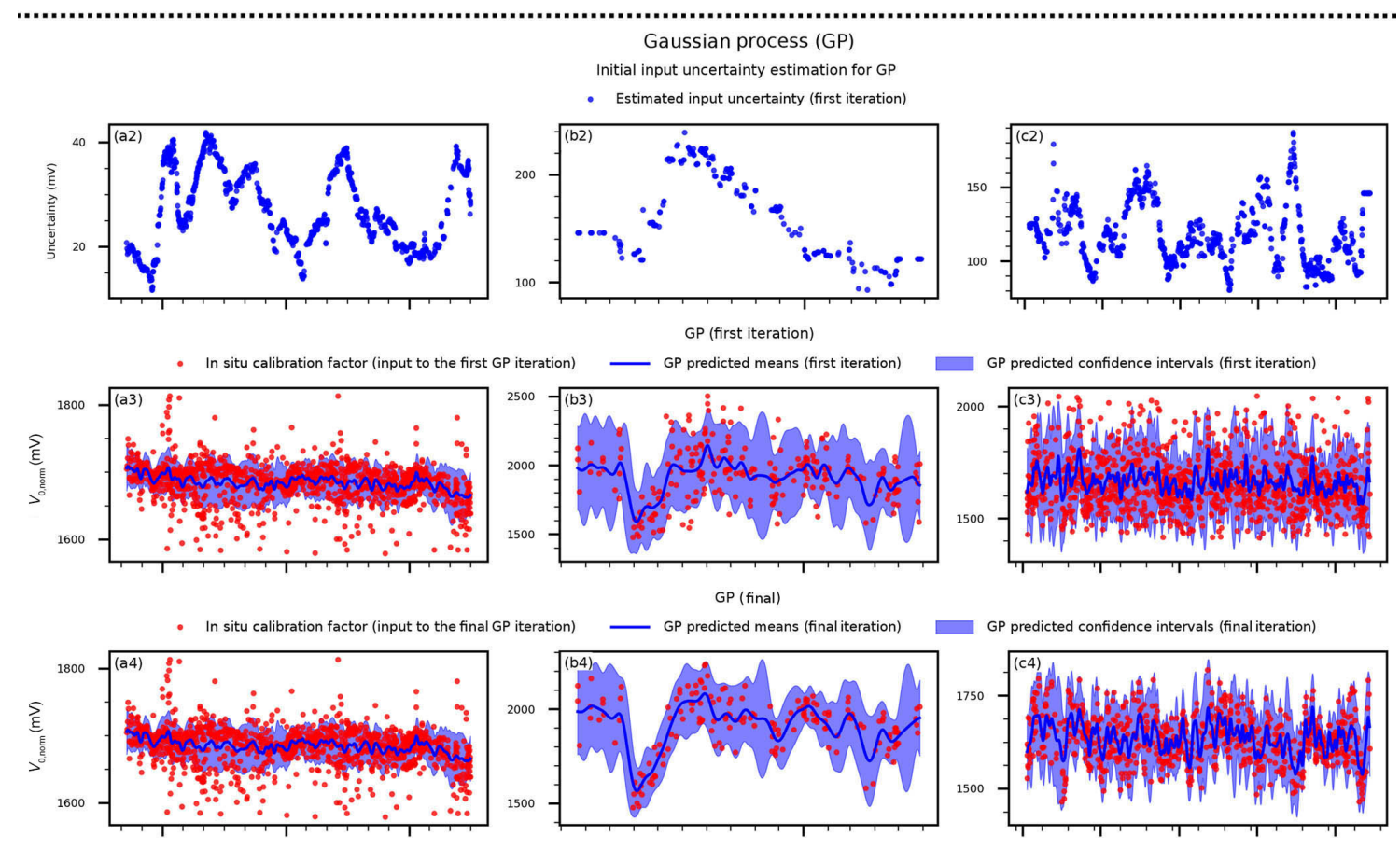

Moving average (MA)

- In situ calibration factor (input to MA) — MA estimated in situ calibration factor
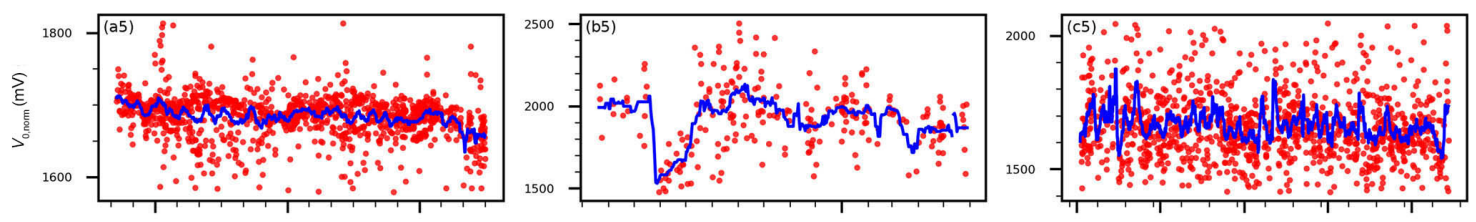

UVMRP OPER

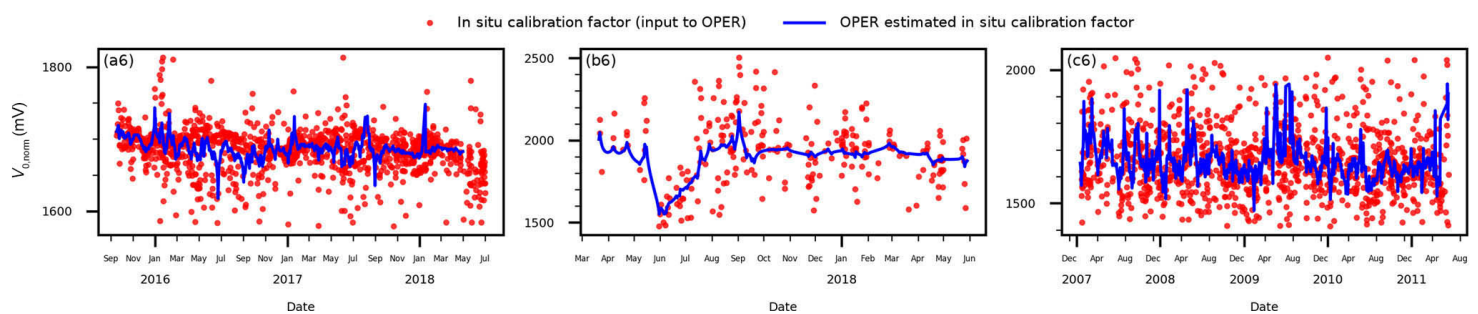

Figure 3. The results of the three smoothing methods (i.e., GP - Gaussian process; MA - moving average; OPER - UVMRP operational algorithm) for the three UVMRP in situ calibration factor sequences: (a) HI02 (17 September 2015 to 1 July 2018), (b) IL02 (21 March 2017 to 29 May 2018), and (c) OK02 (17 January 2007 to 11 June 2011). Panels (a1), (b1), (c1) display the original in situ calibration factor $\left(V_{0, \text { norm }}\right)$ sequence. Panels (a2), (b2), (c2) show the initial input uncertainty estimated for GP. Panels (a3), (b3), (c3) present the predicted daily mean and confidence interval from the first iteration of GP. Panels (a4), (b4), (c4) show the final results of GP after iterations. Panels (a5), (b5), (c5) show the results of MA. Panels (a6), (b6), (c6) show the results of OPER. 


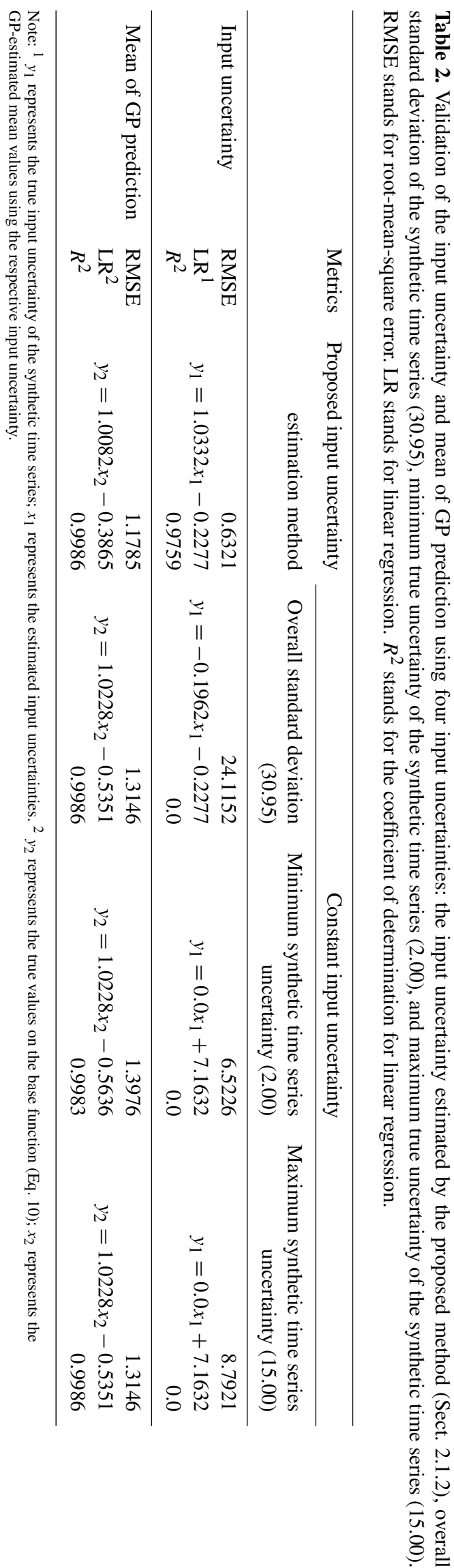

than other UVMRP sites and its $V_{0 \text {, norm }}$ has the lowest variation (Fig. 3a1). The Illinois site (IL02) is surrounded by croplands/rangelands with the closest city (Champaign) located $12 \mathrm{~km}$ northwest (Fig. 3b1). The Oklahoma site (OK02) is also surrounded by croplands/rangelands with the closest city (Oklahoma City) located about $96 \mathrm{~km}$ south (Fig. 3c1). Both wildfires and agricultural activities (e.g., cultivation and harvest) at IL02 and OK02 contribute to the relatively hazy and unstable atmosphere condition for Langley regression. As a result, $V_{0, \text { norm }}$ values at IL02 and OK02 have larger variation compared with HI02. The dynamic input uncertainty estimation results confirm that the uncertainty at HIO2 (1540; Fig. 3a2) is also lower than at the other two sites (100300; Fig. 3b2, c2). Generally, the proposed method gives lower uncertainty values for time windows with more clustered points (e.g., December 2008 and April 2010 at OK02, Fig. 3c2; February 2017 at HI02, Fig. 3a2). There are no obvious temporal patterns of uncertainty at any of the three sites.

Figure 3a3, b3, and c3 show the estimated means (dark blue line) and confidence intervals (light blue area) after the initial pass through GP. The length scale parameters of the RQ kernel for the HIO2, IL02, and OK02 sites are 6.091, 6.369 , and 6.228 (days), respectively. Their corresponding alpha parameters of the RQ kernel function are all close to 1.0 (i.e., $0.948,0.862$, and 0.944 , respectively). As expected, the confidence interval is narrower near time windows with more data points, and the confidence intervals are wider near gaps (Fig. 3b3).

As depicted in Fig. 1, the outlier removal and GP are repeated following the initial GP regression, giving the final GP results shown in Fig. 3a4, b4, and c4. After this final pass, the length scale parameters of the RQ kernel function for the HI02, IL02, and OK02 sites are 6.091, 11.149, and 6.907 (days), respectively. Compared with the first round, all length scale parameters increase as more outliers are removed (except for HI02). At HI02, the average ratio between GP means and standard deviations is lower than the threshold (i.e., 0.01) after the first round and the iteration stops. The corresponding alpha parameters of the RQ kernel function are still all close to 1.0 (i.e., $0.948,1.010$, and 1.110, respectively). Because of outlier removal, compared with the first-round results, GP generates smoother mean functions and narrower confidence intervals at the last round.

The other two methods (i.e., MA and OPER) are applied to the same in situ calibration time series. They can provide mean functions but not confidence intervals. The MA (win_size $=20$ ) results (Fig. 3a5, b5, and c5) are generally smoother than OPER (Fig. 3a6, b6, and c6) but both are more responsive to noisy points than GP. In addition, since OPER is scheduled to run once per month on active deployments, there may be some lags at the end of those deployments (e.g., Fig. 3a6). 

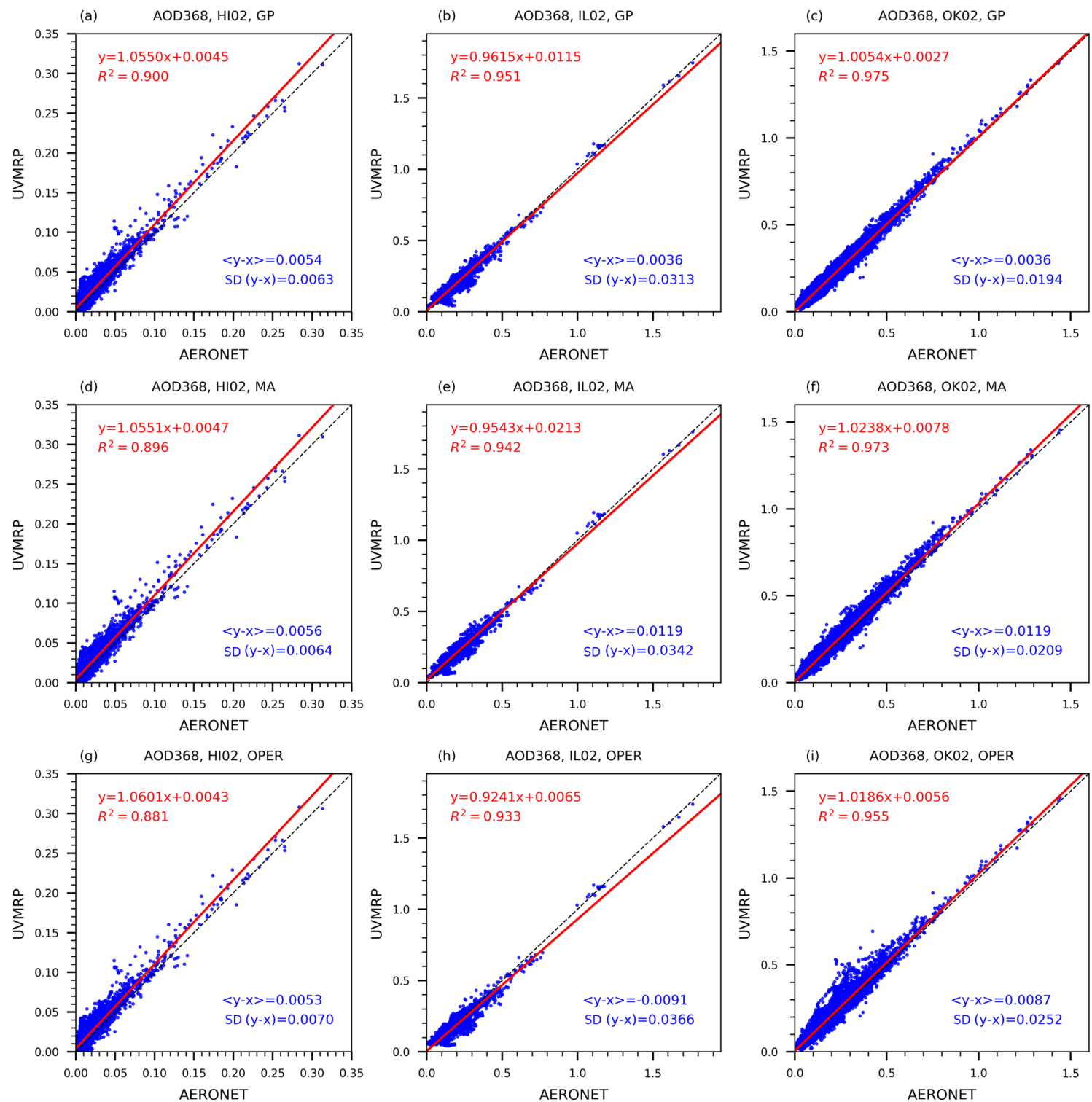

Figure 4. The $368 \mathrm{~nm}$ AOD scatter plots between UVMRP ( $y$ axis) and AERONET ( $x$ axis). The UVMRP $368 \mathrm{~nm}$ AODs are calculated from UV-MFRSR direct normal voltages using calibration factors estimated by the three methods (i.e., from top to bottom: GP, MA, OPER) at the three sites (i.e., from left to right: HI02, IL02, OK02). Panels (a), (b), and (c) display the scatter plots for the GP method at HI02, IL02, and Ok02, respectively. Similarly, panels (c), (c), and (f) are for the MA method and panels (g), (h), and (i) are for the OPER method. The AERONET $368 \mathrm{~nm}$ AODs are derived from collocated (i.e., Mauna_Loa, BONDVILLE, Cart_Site) AERONET AODs on the 340 and $380 \mathrm{~nm}$ channels. The linear regression line (solid, red) and the 1-by-1 line (dashed, black) are also plotted. " $<y-x>$ " means the average difference between AERONET and UVMRP AOD at the $368 \mathrm{~nm}$ channel. "SD $(y-x)$ " means the standard deviation of their difference.

\subsubsection{Validation}

Following the procedures described in Sect. 2.4, the UVMRP AODs at the $368 \mathrm{~nm}$ channel generated by GP, MA, and OPER are validated against the corresponding AERONET AODs at the three collocated sites (i.e., HIO2 - Mauna_Loa, IL02 - BONDVILLE, OK02 - Cart_Site). The scatter plots between these UVMRP and AERONET AODs are displayed in Fig. 4. The performance of all three methods at HIO2
(Fig. 4a, d, g) are similar. For example, the average bias " $<y-x>$ " is approximately 0.0054 and standard deviation of the difference " $\mathrm{SD}(y-x)$ " is approximately 0.0066 . For IL02 (Fig. 4b, e, h) and OK02 (Fig. 4c, f, i), GP shows superior agreements with AERONET to that of the other two methods. For example, at IL02, the absolute value of GP's average bias (0.0036) is about 3.3 to 2.5 times lower than that of MA (0.0119) and OPER (0.0091). Similarly, at OK02, the average bias for GP (0.0032) is much lower than that for MA 
HIO2

(a)

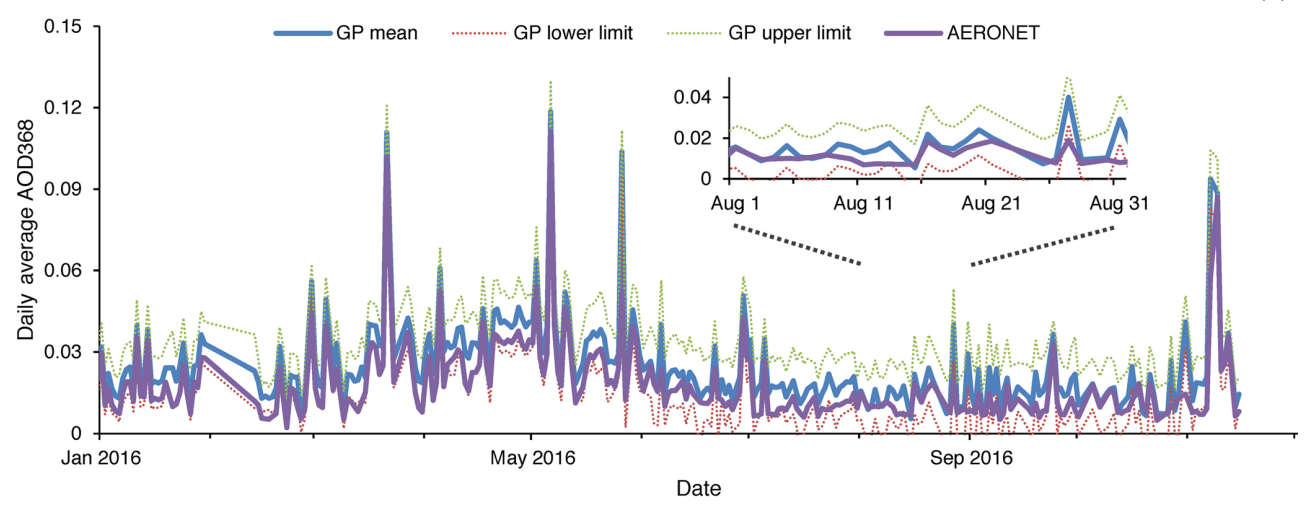

IL02

(b)

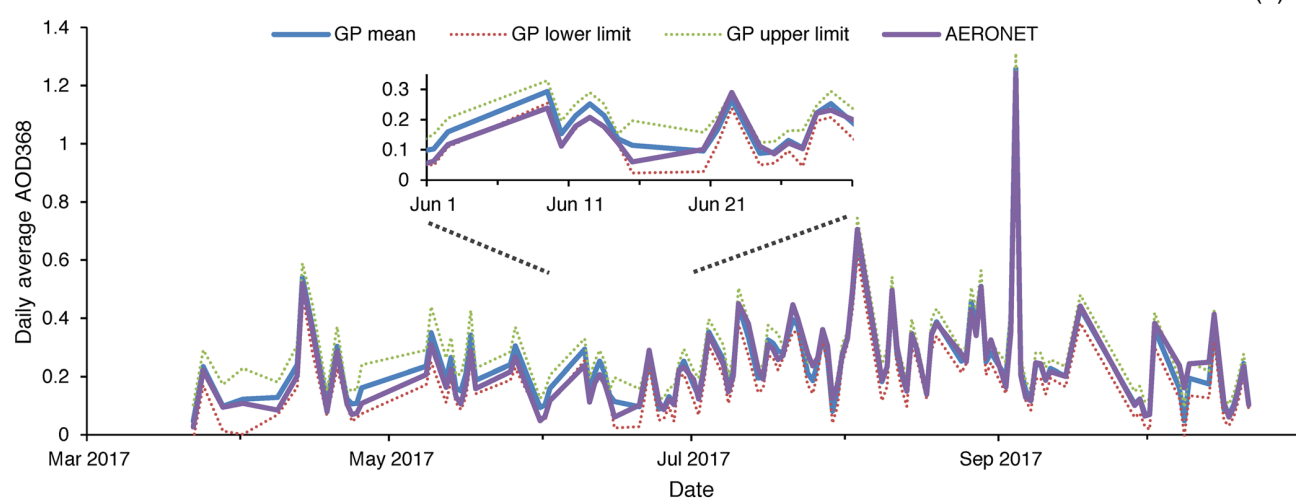

OK02

(C)

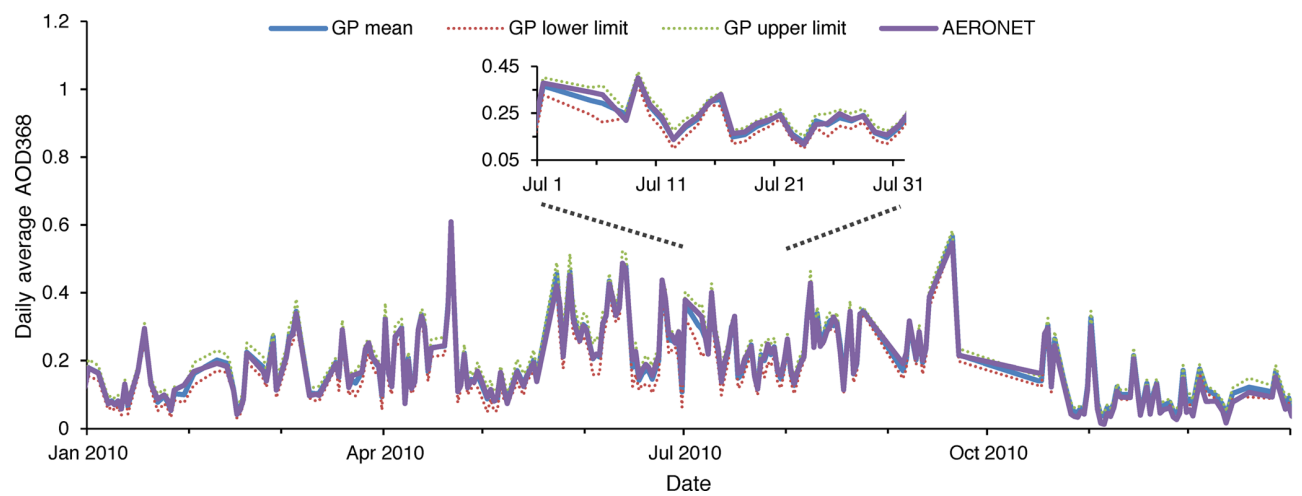

Figure 5. Time series of UVMRP and AERONET $368 \mathrm{~nm}$ daily average AOD at the HIO2, IL02, and OK02 sites. The daily AOD mean values derived from the GP mean in situ calibration factor $\left(V_{0}\right)$ functions (blue) and the corresponding AERONET values (purple) are shown as solid blue lines. The corresponding lower and upper limits of AOD derived from the GP $V_{0}$ confidence intervals are shown as dotted red and green lines, respectively. The insets for HI02 (August 2016), IL02 (June 2017), and OK02 (July 2010) are also included in the respective subplots to show the comparison details.

(0.0119) and OPER (0.0087). The validation results for GP at OK02 are similar to the previous comparison results between AERONET and MFRSR AODs at 415 and $440 \mathrm{~nm}$ (Tang et al., 2013; Alexandrov et al., 2008). Furthermore, as shown in Appendix C, the GP method improves agreement between UVMRP and AERONET $368 \mathrm{~nm}$ AOD across all air masses.
Table 3 shows two additional statistical metrics for validation: " $\operatorname{Avg}\left(\left|\mathrm{AOD}_{368, \mathrm{UVMRP}}-\mathrm{AOD}_{368, \mathrm{AE}}\right|\right)$ ", a measure of absolute difference between the two quantities and "Avg $\left(\left|\mathrm{AOD}_{368, \mathrm{UVMRP}}-\mathrm{AOD}_{368, \mathrm{AE}}\right| / \mathrm{AOD}_{368, \mathrm{AE}}\right)$ " a measure of relative difference between the two quantities. For HI02, the GP $V_{0, \text { norm }}$ values improve both the absolute and relative differences between $\mathrm{AOD}_{368, \mathrm{UVMRP}}$ and $\mathrm{AOD}_{368, \mathrm{AE}}$ 
Table 3. Statistical metrics (average absolute difference, average absolute relative difference, and linear regression) on comparing $368 \mathrm{~nm}$ AOD between UVMRP (AOD 368 ,UVMRP) and AERONET (AOD $368, \mathrm{AE})$. The UVMRP $368 \mathrm{~nm}$ AODs at the three sites (i.e., HI02, IL02, and OK02) are calculated using calibration factors estimated using the three methods (i.e., GP, MA, and OPER). The AERONET $368 \mathrm{~nm}$ AODs are derived from collocated (i.e., Mauna_Loa, BONDVILLE, and Cart_Site) AERONET AODs on the 340 and $380 \mathrm{~nm}$ channels. LR stands for linear regression. $R^{2}$ stands for the coefficient of determination for linear regression. The " $x$ " and " $y$ " in $\mathrm{LR}_{\mathrm{R}}$ refer to $\mathrm{AOD} 368, \mathrm{AE}$ and $\mathrm{AOD}_{368, \mathrm{UVMRP}}$ of the respective methods.

\begin{tabular}{|c|c|c|c|c|}
\hline \multirow{2}{*}{ Site } & \multirow{2}{*}{ Metrics } & \multicolumn{3}{|c|}{ Method } \\
\hline & & GP & MA & OPER \\
\hline \multirow{4}{*}{ HI02 } & \multirow{4}{*}{$\begin{array}{l}\operatorname{Avg}\left(\left|\mathrm{AOD}_{368, \mathrm{UVMRP}}-\mathrm{AOD}_{368, \mathrm{AE}}\right|\right) \\
\operatorname{Avg}\left(\frac{\left|\mathrm{AOD}_{368, \mathrm{UVMRP}}-\mathrm{AOD}_{368, \mathrm{AE}}\right|}{\mathrm{AOD}_{368, \mathrm{AE}}}\right) \\
\mathrm{LR} \\
R^{2}\end{array}$} & 0.0062 & 0.0065 & 0.0067 \\
\hline & & 0.5803 & 0.6078 & 0.6261 \\
\hline & & $y=1.0550 x+0.0045$ & $y=1.0551 x+0.0047$ & $y=1.0601 x+0.0043$ \\
\hline & & 0.9000 & 0.8957 & 0.8812 \\
\hline \multirow{4}{*}{ IL02 } & \multirow{4}{*}{$\begin{array}{l}\operatorname{Avg}\left(\left|\mathrm{AOD}_{368, \mathrm{UVMRP}}-\mathrm{AOD}_{368, \mathrm{AE}}\right|\right) \\
\operatorname{Avg}\left(\frac{\left|\mathrm{AOD}_{368, \mathrm{UVMRP}}-\mathrm{AOD}_{368, \mathrm{AE}}\right|}{\mathrm{AOD}_{368, \mathrm{AE}}}\right) \\
\mathrm{LR} \\
R^{2}\end{array}$} & 0.0228 & 0.0291 & 0.0270 \\
\hline & & 0.1669 & 0.2087 & 0.1930 \\
\hline & & $y=0.9615 x+0.0115$ & $y=0.9543 x+0.0213$ & $y=0.9241 x+0.0065$ \\
\hline & & 0.9514 & 0.9420 & 0.9332 \\
\hline \multirow{4}{*}{ OK02 } & \multirow{4}{*}{$\begin{array}{l}\operatorname{Avg}\left(\left|\mathrm{AOD}_{368, \mathrm{UVMRP}}-\mathrm{AOD}_{368, \mathrm{AE}}\right|\right) \\
\operatorname{Avg}\left(\frac{\left|\mathrm{AOD}_{368, \mathrm{UVMRP}}-\mathrm{AOD}_{368, \mathrm{AE}}\right|}{\mathrm{AOD}_{368, \mathrm{AE}}}\right) \\
\mathrm{LR} \\
R^{2}\end{array}$} & 0.0150 & 0.01785 & 0.01847 \\
\hline & & 0.1714 & 0.2067 & 0.1939 \\
\hline & & $y=1.0054 x+0.0027$ & $y=1.0238 x+0.0078$ & $y=1.0186 x+0.0056$ \\
\hline & & 0.9749 & 0.9726 & 0.9554 \\
\hline
\end{tabular}

when compared to MA (by 4.5\%) and OPER AODs (by $\sim 7.5 \%$ ), respectively. Results from LRs performed between AOD 368, UVMrP and AOD $368, \mathrm{AE}$ are also reported in Table 3. The LR results are similar between GP and MA, but GP has a LR slope closer to 1 (1.0550) and higher $R^{2}(0.9000)$ than those of OPER (1.0601 and 0.8812) for HI02. For IL02, GP shows $21.6 \%$ smaller absolute difference and $20.0 \%$ smaller relative difference to AERONET than MA; GP shows $15.6 \%$ smaller absolute difference and $13.5 \%$ smaller relative difference to AERONET than OPER. Similarly, for OK02, GP shows $16.0 \%$ smaller absolute difference and $17.1 \%$ smaller relative difference to AERONET than MA; GP shows $18.8 \%$ smaller absolute difference and $11.6 \%$ smaller relative difference to AERONET than OPER.

Overall, the $368 \mathrm{~nm}$ AODs by GP show higher correlation, closer to 1 slopes, and lower absolute and relative biases compared to AERONET AODs than MA and OPER at all three sites. The improvement of GP over MA and OPER at IL02 and OK02 is more significant than at HI02. The main reason may be that $\mathrm{HIO} 2$ is the least polluted site among the three sites. Both of its maximum and mean $368 \mathrm{~nm}$ AOD values are low: 0.35 and 0.016, respectively. As a result, higher accuracy of Rayleigh and other optical depth components is required to discern small improvement in AOD for HI02. Since AERONET's sun photometer is routinely calibrated, the agreement on AOD values suggests that the calibration factor mean functions generated by GP are more accurate than those of MA and OPER.
In addition, Fig. 5 shows the $368 \mathrm{~nm}$ AOD time series calculated using GP-generated in situ calibration factors at the three UVMRP sites. The blue solid line represents the AODs calculated using the GP means, and the green and red dotted lines represent the AODs calculated using the GP confidence intervals. It is seen that the AOD confidence intervals are approximately $\pm 0.0095, \pm 0.0480$, and \pm 0.0273 at HI02, IL02, and OK02, respectively. The corresponding AERONET AOD time series are also plotted (i.e., purple lines in Fig. 5). The insets in Figure 5 show comparison details at HI02, IL02, and OK02. For most of the AOD time series, AERONET results are within the GP confidence intervals. The average absolute differences of daily AOD values between GP and AERONET are $\sim 0.006$ for HI02, 0.024 for IL02, and $\sim 0.014$ for OK02. These values are close to or within the AERONET AOD uncertainty level (i.e., 0.01), suggesting the high quality of the potential UVMRP AOD product. In addition, unlike the obvious seasonal changes in AOD difference reported in the previous study at the NASA/GSFC site by Krotkov et al. (2005a), this study (Fig. 5) shows no discernible seasonal pattern in the AOD differences at all three sites.

\section{Conclusions}

A new dynamic uncertainty estimation method for noisy time series is developed in this study. Combining this method with Gaussian process regression, we provide a solution to estimate the underlying mean and uncertainty functions of 
time series with variable mean, noise, sampling density, and length of gaps. For the synthetic case with linear, quadratic, and cubic base functions; a noise level varying from 2 to 15 ; and noticeable gaps, the proposed solution returns a mean function with the RMSE of 1.1785 (linear regression $R^{2}$ of 0.9986), which is at least $12.0 \%$ lower than RMSEs associated with the three constant input uncertainties. Its estimated input uncertainties determined by this method are close to the true uncertainty levels except for the transitional region between segments. The solution also gives accurate mean values at the three gaps. The proposed GP solution as well as the other two comparison methods (i.e., MA and OPER) were then applied to three in situ calibration factor time series of UV-MFRSR ( $368 \mathrm{~nm}$ ) at three UVMRP sites. The GP solution handles the variation in slope, noise, sampling density, and length of gap in the three cases as expected. Since irradiance at $368 \mathrm{~nm}$ is not measured by a collocated (and calibrated) radiometer, the performance of the three methods is validated against the collocated AERONET sites in terms of AOD. The results show that AODs calculated using GPderived UV-MFRSR calibration factors $\left(V_{0, \text { norm }}\right)$ have consistently better agreement with AERONET AODs than MA and OPER in terms of average absolute and relative differences and linear regression $R^{2}$ values. These results suggest that the proposed GP solution is a robust method for time series analyses of data with variable mean, noise, sampling density, and length of gap and has potential for application across disciplines. 


\section{Appendix A: The formulation between the overall standard deviation and the subgroup standard deviation}

Given a time series $\left\{x_{\mathrm{i}}\right\}$, its total $N$ points are divided into $J$ groups $\left\{x_{k}^{j}\right\}$, and the number of points in group $j$ is $N_{j}$ $\left(j=1,2, \ldots, J ; k=1,2, \ldots, N_{j}\right)$. For data points in each group, their sample mean and standard deviation are $\mu_{j}$ and $s_{j}$. For the entire time series, its sample mean is $\mu=\frac{1}{N} \sum_{i=1}^{N} x_{\mathrm{i}}$, and the sample variance is

$$
\begin{aligned}
s^{2} & =\frac{1}{N-1} \sum_{j=1}^{J} \sum_{k=1}^{N_{j}}\left(x_{k}^{j}-\mu\right)^{2} \\
& =\frac{1}{N-1} \sum_{j=1}^{J} \sum_{k=1}^{N_{j}}\left[\left(x_{k}^{j}-\mu_{j}\right)+\left(\mu_{j}-\mu\right)\right]^{2} \\
& =\frac{1}{N-1} \sum_{j=1}^{J} \sum_{k=1}^{N_{j}}\left(x_{k}^{j}-\mu_{j}\right)^{2}+\frac{1}{N-1} \sum_{j=1}^{J} \sum_{k=1}^{N_{j}}\left(\mu_{j}-\mu\right)^{2} \\
& +\frac{2}{N-1} \sum_{j=1}^{J} \sum_{k=1}^{N_{j}}\left(x_{k}^{j}-\mu_{j}\right)\left(\mu_{j}-\mu\right) \\
& =\frac{1}{N-1} \sum_{j=1}^{J} N_{j} s_{j}^{2}+\frac{1}{N-1} \sum_{j=1}^{J} N_{j}\left(\mu_{j}-\mu\right)^{2},
\end{aligned}
$$

where the third term on the right-hand side is equal to zero because $\sum_{k=1}^{N_{j}}\left(x_{k}^{j}-\mu_{j}\right)=0$ (i.e., $\mu_{j}=\frac{1}{N_{j}} \sum_{k=1}^{N_{j}} x_{k}^{j}$ ). If we assume that the sample standard deviation of each data point is invariant (i.e., $s_{1}=s_{2}=\cdots=s_{J}=\hat{s}$ ), then

$s^{2}=\frac{N-J}{N-1} \hat{s}^{2}+\frac{1}{N-1} \sum_{j=1}^{J} N_{j}\left(\mu_{j}-\mu\right)^{2}$.

\section{Appendix B: The distribution of the $368 \mathrm{~nm}$ in situ calibration factors of UV-MFRSR}

Since the true $368 \mathrm{~nm}$ in situ calibration factors are not available, their distribution is derived using the AERONET $368 \mathrm{~nm}$ AOD distribution via Beer's law (transformed Langley regression).

Beer's law links the irradiance (or voltage, $V$ ) at the top of the atmosphere with the one that reaches the ground at time $t$ with the equation $V_{t}=V_{0} e^{-\mathrm{TOD}_{t} \cdot m_{t}}$, where $m_{t}$ is the air mass at time $t$ and $\mathrm{TOD}_{t}$ is the corresponding total optical depth. For the $368 \mathrm{~nm}$ channel, AOD is the main contributor for the TOD variation. Therefore, for a short time period, $\mathrm{TOD}_{t}$ can be expressed as the sum of a constant optical depth $(\bar{P})$ and variable residual $\mathrm{AOD}\left(\triangle \mathrm{AOD}_{t}=\mathrm{AOD}_{t}-\overline{\mathrm{AOD}}\right)$ : $\mathrm{TOD}_{t}=\bar{P}+\Delta \mathrm{AOD}_{t}$. Deriving an unbiased $V_{0}$ using the Langley regression (in the transformed $\operatorname{lnV} \cdot \mathrm{m}^{-1}$ vs. $\mathrm{m}^{-1}$ coordinate system) requires the participating measurements to have a constant $\mathrm{TOD}_{t}$ over the calibration period and $\ln V_{0}$ is the slope of the regression. The variation in $\Delta \mathrm{AOD}_{t}$ as a linear function of the component vary linearly with $m_{t}^{-1}$ (Chen et al., 2014). Therefore, we decompose $\Delta \mathrm{AOD}_{t}$ as the sum of a constant term $(\alpha)$ and a $m_{t}^{-1}$ term $\left(\beta m_{t}^{-1}\right)$, where $\alpha$ and $\beta$ are obtained from daily AERONET $368 \mathrm{~nm}$ AOD measurements via linear regression. With the $\mathrm{TOD}_{t}$ components expanded, the original Beer's law equation is expressed as $\ln V_{t} \cdot m_{t}^{-1}=-(\bar{P}+\alpha)+\left(\ln V_{0}-\beta\right) m_{t}^{-1}$ and the (transformed) Langley regression obtains the slope $\left(\ln \widetilde{V}_{0}=\right.$ $\left.\ln V_{0}-\beta\right)$ via linear regression. The disturbed distribution of $\widetilde{V}_{0}$ is the same as the distribution of $\exp \left(\ln V_{0}-\beta\right)$. Assuming the true $V_{0}$ is $1500 \mathrm{mV}$ (a typical value at OK02) and using a long-term set of $\beta$ values from AERONET at Cart_Site (17 January 2007 to 11 June 2011), a set of $\widetilde{V}_{0}$ is obtained. Removing the tails on the distribution of $\widetilde{V}_{0}$ (i.e., $\widetilde{V}_{0}<1200$ or $\widetilde{V}_{0}>1800$ ), the normal test of the $\widetilde{V}_{0}$ set (using the Python function scipy.stats.normaltest (D'Agostino and Pearson, 1973)) returns the $p$ value of 0.4689 , which is greater than the threshold $\left(10^{-3}\right)$, suggesting that the $\widetilde{V}_{0}$ set comes from a normal distribution. 
Appendix C: Comparison of UVMRP and AERONET

$368 \mathrm{~nm}$ AOD differences as a function of air mass among

the three methods
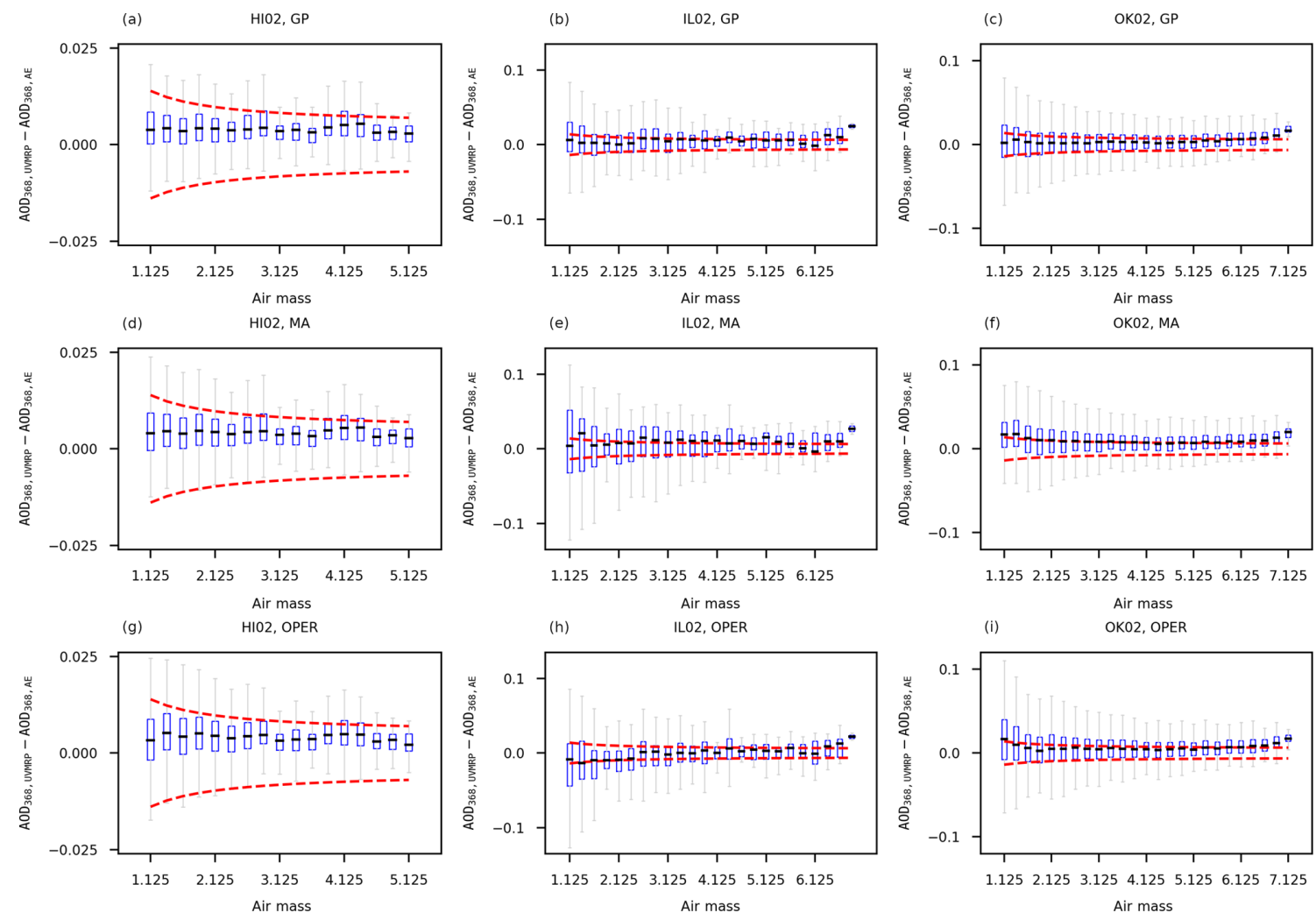

Figure C1. Box-and-whisker plots of $\mathrm{AOD}_{368, \mathrm{UVMRP}}-\mathrm{AOD}_{368, \mathrm{AE}}$ as a function of air mass by the three methods (i.e., from top to bottom: GP, MA, OPER) at the three test sites (i.e., from left to right: HI02, IL02, OK02). Panels (a), (b), and (c) display the box-and-whisker plots for the GP method at HI02, IL02, and OK02, respectively. Similarly, panels (d), (e), and (f) are for the MA method and panels (g), (h), and (i) are for the OPER method. Each blue bin covers a 0.25 air mass range. The dashed red lines show the WMO AOD U95 upper and lower limits.

Figure $\mathrm{C} 1$ showed that GP had narrower error ranges compared with the other two methods (i.e., MA and OPER) at all three test sites (i.e., HI02, IL02, and OK02). The median values (the short black lines in blue boxes) of GP are closer to zero at IL02 and OK02 sites, especially for lower air masses. However, regardless of site, air mass, and method, the difference between AERONET and UV-MFRSR AODs still exceeds the WMO AOD U95 criterion for a number of instances. 
Data availability. The in situ calibration factors (sun-earth distance normalized) used in this study are available from the UVMRP website: http://uvb.nrel.colostate.edu/UVB/da_queryVoIntercepts. jsf (last access: 8 August 2018). The cosine-corrected voltage and air mass are available from https://uvb.nrel.colostate.edu/UVB/da queryCosCorrected.jsf (last access: 8 August 2018). The spectral response functions of the UV-MFRSRs are available from http://uvb.nrel.colostate.edu/UVB/da_queryFilterFunctions.jsf (last access: 8 August 2018). The site latitudes and heights of the three UMVRP sites tested in this study are available from https: //uvb.nrel.colostate.edu/UVB/uvb-siteinfo.jsf (last access: $8 \mathrm{Au}$ gust 2018). The AERONET (v2.0) data (i.e., aerosol optical depth and surface pressure) used in this study are available from https:// aeronet.gsfc.nasa.gov/cgi-bin/webtool_opera_v2_new (last access: 31 July 2018). These web sites provide their data freely to the public. Data may be acquired by utilizing several download methods and options.

Author contributions. $\mathrm{MC}$ and $\mathrm{ZS}$ are equally significant contributors to the research. The methodology was developed by MC and $\mathrm{ZS}$. The software was developed by MC. The results were analyzed by MC, ZS, CAC, and JMD and were validated by MC, ZS, and YAL. The original draft was written by MC and ZS and was reviewed and edited by MC, ZS, CAC, JMD, YAL, and WG. The project was supervised and administered by JMD and WG. The funding for the project was acquired by WG.

Competing interests. The authors declare that they have no conflict of interest.

Acknowledgements. This work is supported by the US Department of Agriculture (USDA) UV-B Monitoring and Research Program, Colorado State University, under USDA National Institute of Food and Agriculture grant 2016-34263-25763. We thank Rick Wagener (PI) and the team for the effort in establishing and maintaining the US Southern Great Plains (SGP) Cloud and Radiation Testbed (CART) site. We thank Brent Holben (PI) and the team for the effort in establishing and maintaining the AERONET Mauna_Loa site. We thank Brent Holben, Christopher M. B. Lehmann, and their team in establishing and maintaining the AERONET BONDVILLE site.

Edited by: Andrew Sayer

Reviewed by: two anonymous referees

\section{References}

Alexandrov, M. D., Lacis, A. A., Carlson, B. E., and Cairns, B.: Remote Sensing of Atmospheric Aerosols and Trace Gases by Means of Multifilter Rotating Shadowband Radiometer. Part I: Retrieval Algorithm, J. Atmos. Sci., 59, 524-543, https://doi.org/10.1175/15200469(2002)059<0524:Rsoaaa>2.0.Co;2, 2002.

Alexandrov, M. D., Marshak, A., Cairns, B., Lacis, A. A., and Carlson, B. E.: Automated cloud screening algo- rithm for MFRSR data, Geophys. Res. Lett., 31, L04118, https://doi.org/10.1029/2003GL019105, 2004.

Alexandrov, M. D., Kiedron, P., Michalsky, J. J., Hodges, G., Flynn, C. J., and Lacis, A. A.: Optical depth measurements by shadowband radiometers and their uncertainties, Appl. Opt., 46, 80278038, https://doi.org/10.1364/AO.46.008027, 2007.

Alexandrov, M. D., Lacis, A. A., Carlson, B. E., and Cairns, B.: Characterization of atmospheric aerosols using MFRSR measurements, J. Geophys. Res.-Atmos., 113, D08204, https://doi.org/10.1029/2007JD009388, 2008.

Augustine, J. A., Cornwall, C. R., Hodges, G. B., Long, C. N., Medina, C. I., and DeLuisi, J. J.: An Automated Method of MFRSR Calibration for Aerosol Optical Depth Analysis with Application to an Asian Dust Outbreak over the United States, J. Appl. Meteorol. Clim., 42, 266-278, https://doi.org/10.1175/15200450(2003)042<0266:Aamomc>2.0.Co;2, 2003.

Augustine, J. A., Hodges, G. B., Cornwall, C. R., Michalsky, J. J., and Medina, C. I.: An Update on SURFRAD - The GCOS Surface Radiation Budget Network for the Continental United States, J. Atmos. Ocean. Tech., 22, 1460-1472, https://doi.org/10.1175/jtech1806.1, 2005.

Bodhaine, B. A., Wood, N. B., Dutton, E. G., and Slusser, J. R.: On Rayleigh Optical Depth Calculations, J. Atmos. Ocean. Technol., 16, 1854-1861, https://doi.org/10.1175/15200426(1999)016<1854:orodc>2.0.co;2, 1999.

Burša, M., Raděj, K., Šima, Z., True, S. A., and Vatrt, V.: Determination of the Geopotential Scale Factor from TOPEX/POSEIDON Satellite Altimetry, Stud. Geophys. Geod., 41, 203-216, https://doi.org/10.1023/a:1023313614618, 1997.

Cardema, J. C., Rausch, K. W., Lei, N., Moyer, D. I., and Luccia, F. J. D.: Operational calibration of VIIRS reflective solar band sensor data records, SPIE Optical Engineering + Applications, San Diego, CA, 6, 2012.

Cebula, R. P., DeLand, M. T., and Schlesinger, B. M.: Estimates of solar variability using the solar backscatter ultraviolet (SBUV) $2 \mathrm{Mg}$ II index from the NOAA 9 satellite, J. Geophys. Res.Atmos., 97, 11613-11620, https://doi.org/10.1029/92JD00893, 1992.

Chandorkar, M., Camporeale, E., and Wing, S.: Probabilistic forecasting of the disturbance storm time index: An autoregressive Gaussian process approach, Space Weather, 15, 1004-1019, https://doi.org/10.1002/2017SW001627, 2017.

Chen, M., Davis, J., Tang, H., Ownby, C., and Gao, W.: The calibration methods for multi-filter rotating shadowband radiometer: a review, Front. Earth Sci., 7, 257-270, https://doi.org/10.1007/s11707-013-0368-9, 2013.

Chen, M., Davis, J., and Gao, W.: A new cloud screening algorithm for ground-based direct-beam solar radiation, J. Atmos. Ocean. Tech., 31, 2591-2605, https://doi.org/10.1175/JTECHD-14-00095.1, 2014.

Chen, M., Davis, J., Sun, Z., and Gao, W.: Two-stage reference channel calibration for collocated UV and VIS Multi-Filter Rotating Shadowband Radiometers, SPIE Optical Engineering + Applications, San Diego, CA, 96100L, 2015.

Chen, M., Zempila, M.-M., Davis, J. M., King, R. W., and Gao, W.: In-situ calibration of the water vapor channel for multi-filter rotating shadowband radiometer using collocated GPS, AERONET and meteorology data, SPIE Optical Engineering + Applications, San Diego, CA, 14, 2016. 
D'Agostino, R. and Pearson, E. S.: Tests for Departure from Normality, Empirical Results for the Distributions of $b_{2}$ and $\mathrm{vb}_{1}$, Biometrika, 60, 613-622, https://doi.org/10.2307/2335012, 1973.

Eaton, M. L.: Multivariate statistics: a vector space approach, Wiley, New York, 1983.

Eck, T. F., Holben, B. N., Reid, J. S., Dubovik, O., Smirnov, A., O'Neill, N. T., Slutsker, I., and Kinne, S.: Wavelength dependence of the optical depth of biomass burning, urban, and desert dust aerosols, J. Geophys. Res.-Atmos., 104, 3133331349, https://doi.org/10.1029/1999JD900923, 1999.

Gao, W., Davis, J. M., Tree, R., Slusser, J. R., and Schmoldt, D.: An Ultraviolet Radiation Monitoring and Research Program for Agriculture, in: UV Radiation in Global Climate Change: Measurements, Modeling and Effects on Ecosystems, edited by: Gao, W., Slusser, J., and Schmoldt, D., Springer, Berlin, Heidelberg, 205-243, 2010.

Harrison, L. and Michalsky, J.: Objective algorithms for the retrieval of optical depths from ground-based measurements, Appl. Opt., 33, 5126-5132, https://doi.org/10.1364/AO.33.005126, 1994.

Holben, B. N., Eck, T. F., Slutsker, I., Tanré, D., Buis, J. P., Setzer, A., Vermote, E., Reagan, J. A., Kaufman, Y. J., Nakajima, T., Lavenu, F., Jankowiak, I., and Smirnov, A.: AERONET - A Federated Instrument Network and Data Archive for Aerosol Characterization, Remote Sens. Environ., 66, 1-16, https://doi.org/10.1016/S0034-4257(98)00031-5, 1998.

Holben, B. N., Tanré, D., Smirnov, A., Eck, T. F., Slutsker, I., Abuhassan, N., Newcomb, W. W., Schafer, J. S., Chatenet, B., Lavenu, F., Kaufman, Y. J., Castle, J. V., Setzer, A., Markham, B., Clark, D., Frouin, R., Halthore, R., Karneli, A., O’Neill, N. T., Pietras, C., Pinker, R. T., Voss, K., and Zibordi, G.: An emerging ground-based aerosol climatology: Aerosol optical depth from AERONET, J. Geophys. Res.-Atmos., 106, 12067-12097, https://doi.org/10.1029/2001JD900014, 2001.

Hyndman, R. J.: Moving Averages, in: International Encyclopedia of Statistical Science, edited by: Lovric, M., Springer, Berlin, Heidelberg, 866-869, 2011.

Kassianov, E. I., Flynn, C. J., Ackerman, T. P., and Barnard, J. C.: Aerosol single-scattering albedo and asymmetry parameter from MFRSR observations during the ARM Aerosol IOP 2003, Atmos. Chem. Phys., 7, 3341-3351, https://doi.org/10.5194/acp-73341-2007, 2007.

Kavetski, D., Kuczera, G., and Franks, S. W.: Bayesian analysis of input uncertainty in hydrological modeling: 2. Application, Water Resour. Res., 42, W03408, https://doi.org/10.1029/2005WR004376, 2006a.

Kavetski, D., Kuczera, G., and Franks, S. W.: Bayesian analysis of input uncertainty in hydrological modeling: 1. Theory, Water Resour. Res., 42, W03407, https://doi.org/10.1029/2005WR004368, 2006b.

Kazadzis, S., Kouremeti, N., Diémoz, H., Gröbner, J., Forgan, B. W., Campanelli, M., Estellés, V., Lantz, K., Michalsky, J., Carlund, T., Cuevas, E., Toledano, C., Becker, R., Nyeki, S., Kosmopoulos, P. G., Tatsiankou, V., Vuilleumier, L., Denn, F. M., Ohkawara, N., Ijima, O., Goloub, P., Raptis, P. I., Milner, M., Behrens, K., Barreto, A., Martucci, G., Hall, E., Wendell, J., Fabbri, B. E., and Wehrli, C.: Results from the Fourth WMO Filter Radiometer Comparison for aerosol opti- cal depth measurements, Atmos. Chem. Phys., 18, 3185-3201, https://doi.org/10.5194/acp-18-3185-2018, 2018.

Kim, S.-W., Jefferson, A., Yoon, S.-C., Dutton, E. G., Ogren, J. A., Valero, F. P. J., Kim, J., and Holben, B. N.: Comparisons of aerosol optical depth and surface shortwave irradiance and their effect on the aerosol surface radiative forcing estimation, J. Geophys. Res.-Atmos., 110, D07204, https://doi.org/10.1029/2004JD004989, 2005.

Kim, S.-W., Yoon, S.-C., Dutton, E. G., Kim, J., Wehrli, C., and Holben, B. N.: Global Surface-Based Sun Photometer Network for Long-Term Observations of Column Aerosol Optical Properties: Intercomparison of Aerosol Optical Depth, Aerosol Sci. Tech., 42, 1-9, https://doi.org/10.1080/02786820701699743, 2008.

Krotkov, N. A., Bhartia, P. K., Herman, J. R., Slusser, J. R., Labow, G. J., Scott, G. R., Janson, G. T., Eck, T., and Holben, B. N.: Aerosol ultraviolet absorption experiment (2002 to 2004), part 1: ultraviolet multifilter rotating shadowband radiometer calibration and intercomparison with CIMEL sunphotometers, Opt. Eng., 44, 041004, https://doi.org/10.1117/1.1886818, 2005a.

Krotkov, N. A., Bhartia, P. K., Herman, J. R., Slusser, J. R., Scott, G. R., Labow, G. J., Vasilkov, A. P., Eck, T., Doubovik, O., and Holben, B. N.: Aerosol ultraviolet absorption experiment (2002 to 2004), part 2: absorption optical thickness, refractive index, and single scattering albedo, Opt. Eng., 44, 041005-041001-041005041017, 2005b.

Kupilik, M. and Witmer, F.: Spatio-temporal violent event prediction using Gaussian process regression, Journal of Computational Social Science, 1, 437-451, https://doi.org/10.1007/s42001-018-0024-y, 2018.

Mather, J. H. and Voyles, J. W.: The Arm Climate Research Facility: A Review of Structure and Capabilities, B. Am. Meteorol. Soc., 94, 377-392, https://doi.org/10.1175/bams-d-11-00218.1, 2013.

Press, W. H.: Numerical recipes in C: the art of scientific computing, 2nd ed., Cambridge University Press, Cambridge Cambridgeshire, New York, 1992.

Proietti, T.: Trend Estimation, in: International Encyclopedia of Statistical Science, edited by: Lovric, M., Springer, Berlin, Heidelberg, 1613-1616, 2011.

Rasmussen, C. E. and Williams, C. K. I.: Gaussian processes for machine learning, Cambridge, MA: MIT Press, Cambridge, MA, USA, 266 pp., 2006.

Richter, P. and Toledano-Ayala, M.: Revisiting Gaussian Process Regression Modeling for Localization in Wireless Sensor Networks, Sensors, 15, 22587-22615, https://doi.org/10.3390/s150922587, 2015.

Shaw, G. E.: Error analysis of multi-wavelength sun photometry, Pure Appl. Geophys., 114, 1-14, https://doi.org/10.1007/bf00875487, 1976.

Slusser, J., Gibson, J., Bigelow, D., Kolinski, D., Disterhoft, P., Lantz, K., and Beaubien, A.: Langley method of calibrating UV filter radiometers, J. Geophys. Res.-Atmos., 105, 4841-4849, https://doi.org/10.1029/1999JD900451, 2000.

Tang, H., Chen, M., Davis, J., and Gao, W.: Comparison of aerosol optical depth of UV-B monitoring and research program (UVMRP), AERONET and MODIS over continental united states, Front. Earth Sci., 7, 129-140, https://doi.org/10.1007/s11707-013-0376-9, 2013. 
Viereck, R. A., Floyd, L. E., Crane, P. C., Woods, T. N., Knapp, B. G., Rottman, G., Weber, M., Puga, L. C., and DeLand, M. T.: A composite Mg II index spanning from 1978 to 2003, Space Weather, 2, 1-13, https://doi.org/10.1029/2004SW000084, 2004.

Wahba, G.: Smoothing Splines, in: International Encyclopedia of Statistical Science, edited by: Lovric, M., Springer, Berlin, Heidelberg, 1349-1353, 2011.

$\mathrm{Wu}, \mathrm{R}$. and Wang, B.: Gaussian process regression method for forecasting of mortality rates, Neurocomputing, 316, 232-239, https://doi.org/10.1016/j.neucom.2018.08.001, 2018.
Yin, B., Min, Q., and Joseph, E.: Retrievals and uncertainty analysis of aerosol single scattering albedo from MFRSR measurements, J. Quant. Spectrosc. Ra., 150, 95-106, https://doi.org/10.1016/j.jqsrt.2014.08.012, 2015.

Zhang, M., Gong, W., Ma, Y., Wang, L., and Chen, Z.: Transmission and division of total optical depth method: A universal calibration method for Sun photometric measurements, Geophys. Res. Lett., 43, 2974-2980, https://doi.org/10.1002/2016GL068031, 2016. 